OPEN ACCESS

Edited by:

Giuseppe Calamita,

University of Bari Aldo Moro, Italy

Reviewed by:

Jean-François Desaphy,

University of Bari Aldo Moro, Italy

Shannon Shields,

Coda Biotherapeutics, Inc.

United States

*Correspondence:

Michel De Waard

michel.dewaard@univ-nantes.fr

Specialty section:

This article was submitted to

Cellular Biochemistry,

a section of the journal

Frontiers in Cell and Developmental

Biology

Received: 20 October 2021 Accepted: 22 November 2021 Published: 20 December 2021

Citation:

Lopez L, Montnach J,

Oliveira-Mendes B, Khakh K,

Thomas B, Lin S, Caumes $C$, Wesolowski S, Nicolas S, Servent D, Cohen $C$, Béroud R, Benoit $E$ and

De Waard M (2021) Synthetic Analogues of Huwentoxin-IV Spider Peptide With Altered Human Nav1.7/

Nav1.6 Selectivity Ratios.

Front. Cell Dev. Biol. 9:798588.

doi: 10.3389/fcell.2021.798588

\title{
Synthetic Analogues of Huwentoxin-IV Spider Peptide With Altered Human Nav1.7/Nav1.6 Selectivity Ratios
}

\begin{abstract}
Ludivine Lopez ${ }^{1}$, Jérôme Montnach ${ }^{1}$, Barbara Oliveira-Mendes ${ }^{1}$, Kuldip Khakh ${ }^{2}$, Baptiste Thomas ${ }^{3}$, Sophia Lin $^{2}$, Cécile Caumes ${ }^{3}$, Steven Wesolowski ${ }^{2}$, Sébastien Nicolas ${ }^{1}$, Denis Servent ${ }^{4}$, Charles Cohen ${ }^{2}$, Rémy Béroud ${ }^{3}$, Evelyne Benoit ${ }^{4}$ and Michel De Waard ${ }^{1,3,5 *}$

${ }^{1}$ L'institut du Thorax, INSERM, CNRS, UNIV NANTES, Nantes, France, ${ }^{2} X e n o n$ Pharmaceuticals, Burnaby, BC, Canada, ${ }^{3}$ Smartox Biotechnology, Saint-Egrève, France, ${ }^{4}$ Département Médicaments et Technologies pour La Santé (DMTS), Service d'Ingénierie Moléculaire pour La Santé (SIMOS), ERL CNRS/CEA, Institut des Sciences du Vivant Frédéric Joliot, CEA, Université Paris Saclay, Gif-sur-Yvette, France, ${ }^{5}$ LabEx « Ion Channels, Science and Therapeutics », Valbonne, France
\end{abstract}

Huwentoxin-IV (HwTx-IV), a peptide discovered in the venom of the Chinese bird spider Cyriopagopus schmidti, has been reported to be a potent antinociceptive compound due to its action on the genetically-validated $\mathrm{Na}_{v} 1.7$ pain target. Using this peptide for antinociceptive applications in vivo suffers from one major drawback, namely its negative impact on the neuromuscular system. Although studied only recently, this effect appears to be due to an interaction between the peptide and the Nav1.6 channel subtype located at the presynaptic level. The aim of this work was to investigate how HwTx-IV could be modified in order to alter the original human (h) Nav1.7/Nav1.6 selectivity ratio of 23 . Nineteen HwTx-IV analogues were chemically synthesized and tested for their blocking effects on the $\mathrm{Na}^{+}$currents flowing through these two channel subtypes stably expressed in cell lines. Dose-response curves for these analogues were generated, thanks to the use of an automated patch-clamp system. Several key amino acid positions were targeted owing to the information provided by earlier structure-activity relationship (SAR) studies. Among the analogues tested, the potency of HwTx-IV E ${ }^{4} \mathrm{~K}$ was significantly improved for $\mathrm{hNa} \mathrm{v}_{\mathrm{V}}$ 1.6, leading to a decreased $\mathrm{hNa} \mathrm{Na}^{1.7 /}$ hNav1.6 selectivity ratio (close to 1). Similar decreased selectivity ratios, but with increased potency for both subtypes, were observed for HwTx-IV analogues that combine a substitution at position 4 with a modification of amino acid 1 or 26 (HWTX-IV E ${ }^{1} G / E^{4} G$ and $H w T x-I V E^{4} K / R^{26} Q$ ). In contrast, increased selectivity ratios (>46) were obtained if the $\mathrm{E}^{4} \mathrm{~K}$ mutation was combined to an additional double substitution $\left(R^{26} \mathrm{~A} \mathrm{Y}^{33} \mathrm{~W}\right)$ or simply by further substituting the C-terminal amidation of the peptide by a carboxylated motif, linked to a marked loss of potency on $\mathrm{hNa} 1.6$ in this latter case. These results demonstrate that it is possible to significantly modulate the selectivity ratio for these two channel subtypes in order to improve the potency of a given analogue for $\mathrm{hNa} \mathrm{Na}_{v} 1.6$ and/or hNav1.7 subtypes. In addition, selective analogues for $\mathrm{hNa} \mathrm{a}_{1} 1.7$, possessing better safety profiles, were produced to limit neuromuscular impairments.

Keywords: huwentoxin-IV analogues, Cyriopagopus schmidti, development of pain therapeutics, $\mathrm{Nav}_{\mathrm{v}} \mathbf{1 . 6}$ and $\mathrm{Na}_{\mathrm{v}} \mathbf{1 . 7}$ channel subtypes, automated patch-clamp, structure-function relationship, peptide synthesis 


\section{INTRODUCTION}

For over 10 years, the $\mathrm{Na}_{\mathrm{V}} 1.7$ channel subtype is considered as an attractive pain target owing to several compelling genetic evidences. Loss-of-function mutations in SCN9A, the gene encoding human (h) $\mathrm{Na}_{\mathrm{V}} 1.7$, lead to congenital insensitivity to pain (referred to as CIP) (Cox et al., 2006). Conversely, gain-offunction mutations of the same gene lead to erythromelalgia and paroxysmal extreme pain disorder (Estacion et al., 2008). Because of these clinical evidences, the $\mathrm{hNa}_{\mathrm{V}} 1.7$ channel has been the target of choice for high-throughput screening campaigns to identify blockers as pain therapeutics. Two types of libraries were used for this purpose: small organic compounds from leading pharmaceutical companies (Macsari et al., 2012; Nguyen et al., 2012; Sun et al., 2014; Focken et al., 2016; Wu et al., 2017; Cuesta and Meneses, 2021) and natural peptides originating from animal venoms (Trim et al., 2021). Indeed, disulfide-bridged peptides, frequently purified from animal venoms, have been considered as interesting lead compounds (Bordon et al., 2020), either as pore blockers or gating modifiers, for the modulation of ion channels in general and the treatment of pain in particular (Cardoso and Lewis, 2018). Owing to chemical spaces larger than those of small molecules, they possess better affinities and selectivity profiles even when the target of interest shares high sequence identity with other ion channel subtypes. This was illustrated by peptides issued from spider venoms, often possessing an Inhibitory Cystine Knot (ICK) fold, that were shown to be able of distinguishing closely related subtypes of $\mathrm{Na}_{\mathrm{V}}$ channels (for reviews, see (Gonçalves et al., 2018a; Cardoso and Lewis, 2019; Dongol et al., 2019)). This ability is facilitated by the interaction of these peptides with the different voltage-sensor domains, known to be the most divergent in sequence in contrast to pore region.

Along with protoxin II (Montnach et al., 2021), one of the best studied inhibitors of $\mathrm{hNa}_{\mathrm{V}} 1.7$ channel is huwentoxin-IV (HwTxIV), a 35 amino acid peptide isolated from the venom of the Chinese bird-eating tarantula spider Cyriopagopus schmidti (Peng et al., 2002). HwTx-IV belongs to the NaSpTx family 1 (Klint et al., 2012) because of its sequence. In addition, according to the ICK motif, this peptide is folded with the Cys ${ }^{2}-\mathrm{Cys}^{17}$, Cys ${ }^{9}-$ $\mathrm{Cys}^{24}$, $\mathrm{Cys}^{16}{ }^{16} \mathrm{Cys}^{31}$ disulfide bridge pattern, which favors the formation of a double-stranded antiparallel beta-sheet $\left(\mathrm{Leu}^{22}\right.$ $\mathrm{Ser}^{25}, \mathrm{Trp}^{30}-\mathrm{Tyr}^{33}$ ) along with four turns $\left(\mathrm{Glu}^{4}-\mathrm{Lys}^{7}, \mathrm{Pro}^{11}-\mathrm{Asp}^{14}\right.$, $\mathrm{Lys}^{18}$-Lys $\left.{ }^{21}, \mathrm{Arg}^{26}-\mathrm{Arg}^{29}\right)$. Overall, this peptide possesses a compact and rigid scaffold (Peng et al., 2002) that confers high protease resistance and thus elevated in vivo stability. Like most other spider toxins, HwTx-IV has been reported to be a gating modifier by interacting with the voltage-sensor domain II of $\mathrm{hNa}_{\mathrm{V}} 1.7$ and trapping it into the closed configuration (Xiao et al., 2008; Xiao et al., 2011; Shen et al., 2019; Gao et al., 2020). This binding was suggested to imply residue $\mathrm{Glu}^{753}$ of the S1-S2 loop and four residues, Glu ${ }^{811}$, Leu ${ }^{814}$, $\mathrm{Asp}^{816}$ and $\mathrm{Glu}^{819}$, of the S3-S4 loop of this channel subtype, which defines an EELDE motif for the toxin interaction. Because of the nature of this complex interaction, HwTx-IV owns de facto good natural selectivity for $\mathrm{hNa}_{\mathrm{V}} 1.7$. However, $\mathrm{hNa}_{\mathrm{V}} 1.1$,
$\mathrm{hNa}_{\mathrm{V}} 1.2, \mathrm{hNa}_{\mathrm{V}} 1.3$ and $\mathrm{hNa}_{\mathrm{V}} 1.6$ channel subtypes are also sensitive to the peptide, while $\mathrm{hNa}_{\mathrm{V}} 1.4, \mathrm{hNa}_{\mathrm{V}} 1.5$ and $\mathrm{hNa}_{\mathrm{V}} 1.8$ are resistant (Rahnama et al., 2017; Gonçalves et al., 2018b). Indeed, the EELDE motif for HwTx-IV binding onto $\mathrm{hNa}_{\mathrm{V}} 1.7$ is preserved in $\mathrm{hNa}_{\mathrm{V}} 1.6$, and only slightly modified (towards an EELNE motif) in $\mathrm{hNa}_{\mathrm{V}} 1.1, \mathrm{hNa}_{\mathrm{V}} 1.2$ and $\mathrm{hNa}_{\mathrm{V}} 1.3$. Many more alterations in this motif are detected in $\mathrm{hNa}_{\mathrm{V}} 1.4, \mathrm{hNa}_{\mathrm{V}} 1.5$ and $\mathrm{hNa}_{\mathrm{V}} 1.8$. These observations are all coherent with the selectivity data (Xiao et al., 2008; Revell et al., 2013; Rahnama et al., 2017; Gonçalves et al., 2018b; Agwa et al., 2020).

Considering the high potency of HwTx-IV for $\mathrm{hNa}_{\mathrm{V}} 1.7$, it was quite logical to test the analgesic potential of the peptide in pain animal models. HwTx-IV was thus reported as an efficient analgesic in rodent models of inflammatory and neuropathic pain (Liu et al., 2014b), as well as of spontaneous pain induced by the $\mathrm{Na}_{\mathrm{V}} 1.7$ activator OD1, the first toxin isolated from the venom of the scorpion Odonthobuthus doriae (Rahnama et al., 2017). However, these encouraging preclinical results hampered clinical development because the peptide also produced evident side effects in vivo resulting from impairment of neuromuscular transmission (Liu et al., 2014a; Deuis et al., 2016; Flinspach et al., 2017; Rahnama et al., 2017). It is only later that this effect was clearly attributed to the activity of HwTx-IV on the $\mathrm{Na}_{V} 1.6$ channel, a subtype localized at presynaptic nerve terminals innervating the muscles (Gonçalves et al., 2018b).

Because of the analgesic potential of HwTx-IV, mainstream efforts have been dedicated to producing analogues with enhanced potency on $\mathrm{hNa}_{\mathrm{V}} 1.7$ (Revell et al., 2013; Rahnama et al., 2017). However, most of earlier studies, if not all, considered the potential effects of the peptide sequence modifications on its selectivity profile towards other $\mathrm{Na}_{V}$ subtypes (in general $\mathrm{Na}_{\mathrm{V}} 1.5$ or $\mathrm{Na}_{\mathrm{V}} 1.2$ ) with the notable exception of the $\mathrm{Na}_{\mathrm{V}} 1.6$ subtype (Minassian et al., 2013; Neff et al., 2020). The present report aims at investigating the relative selectivity of HwTx-IV and 19 synthetic analogues on both $\mathrm{hNa}_{\mathrm{V}} 1.7$ and $\mathrm{hNa}_{\mathrm{V}} 1.6$ channel subtypes. All these analogues were designed on the basis of earlier SAR investigations and mainly by focusing on amino acid residues shown to influence the $\mathrm{hNa}_{\mathrm{V}} 1.7 / \mathrm{hNa}_{\mathrm{V}} 1.2$ selectivity ratio. Two goals were pursued: 1) identify analogues with improved selectivity for $\mathrm{hNa}_{\mathrm{V}} 1.7$, and 2) identify new analogues that have improved potencies for $\mathrm{hNa}_{\mathrm{V}}$ 1.6. For this purpose, similar experimental conditions for chemical syntheses and functional evaluations were employed to get reliable and exploitable results. Under these conditions, 11 analogues with increased apparent affinity for $\mathrm{hNa}_{\mathrm{V}} 1.6$ were identified, among which 4 improved the half maximal inhibitory concentration $\left(\mathrm{IC}_{50}\right)$ values by more than 36 -fold without drastically decreasing the peptide potency for $\mathrm{hNa}_{\mathrm{V}}$ 1.7. Conversely, 7 analogues increased the apparent affinity for $\mathrm{hNa}_{\mathrm{V}} 1.7$, while only one of them had a decreased potency for $\mathrm{hNa}_{\mathrm{V}} 1.6$. These data illustrate that adequately mutating HwTx-IV contributes to large improvements of the peptide potency for $\mathrm{hNa}_{\mathrm{V}} 1.6$, while in parallel mildly improving the potency for $\mathrm{hNa}_{\mathrm{V}}$ 1.7. This process reaches the point at which the potencies of some of the analogues are similar, in the low nanomolar range, for both channel subtypes. 


\begin{tabular}{|c|c|c|}
\hline Peptides & Sequences & MM (Da) \\
\hline & & \\
\hline HwTx-IV WT & ECLEIFKACNPSNDQCCKSSKLVCSRKTRWCKYQI * & 4107.20 \\
\hline$H w T x-I V \quad E^{1} G$ & GCLEIFKACNPSNDQCCKSSKLVCSRKTRWCKYQI* & 4031.93 \\
\hline$H w T x-I V \quad E^{4} G$ & ECLGIFKACNPSNDQCCKSSKLVCSRKTRWCKYQI* & 4031.93 \\
\hline$H w T x-I V \quad E^{4} K$ & ECLKIFKACNPSNDQCCKSSKLVCSRKTRWCKYQI * & 4103.01 \\
\hline$H w T x-I V E^{4} R$ & ECLRIFKACNPSNDQCCKSSKLVCSRKTRWCKYQI* & 4131.01 \\
\hline $\mathrm{HwTx}-\mathrm{IV} \mathrm{K}^{18} \mathrm{~A}$ & ECLEIFKACNPSNDQCCASSKLVCSRKTRWCKYQI * & 4046.89 \\
\hline $\mathrm{HwTx}-\mathrm{IV} \quad \mathrm{K}^{32} \mathrm{~N}$ & ECLEIFKACNPSNDQCCKSSKLVCSRKTRWCNYQI * & 4089.89 \\
\hline$H w T x-I V \quad R^{26} A$ & ECLEIFKACNPSNDQCCKSSKLVCSAKTRWCKYQI* & 4018.89 \\
\hline $\mathrm{HwTx}-\mathrm{IV} \mathrm{R}^{26} \mathrm{Q}$ & ECLEIFKACNPSNDQCCKSSKLVCSQKTRWCKYQI* & 4075.91 \\
\hline $\mathrm{HwTx}-\mathrm{IV} \mathrm{T}^{28} \mathrm{~W}$ & ECLEIFKACNPSNDQCCKSSKLVCSRKWRWCKYQI* & 4188.98 \\
\hline $\mathrm{HWTX}-\mathrm{IV} \quad \mathrm{Y}^{33} \mathrm{~W}$ & ECLEI FKACNPSNDQCCKSSKLVCSRKTRWCKWQI * & 4126.97 \\
\hline$H w T x-I V \quad E^{1} G / E^{4} G$ & GCLGIFKACNPSNDQCCKSSKLVCSRKTRWCKYQI* & 3959.91 \\
\hline $\mathrm{HwTx}-\mathrm{IV} \mathrm{E}^{4} \mathrm{R} / \mathrm{K}^{32} \mathrm{~N}$ & ECLRIFKACNPSNDQCCKSSKLVCSRKTRWCNYQI* & 4116.95 \\
\hline$H w T x-I V \quad E^{4} K / R^{26} Q$ & ECLKIFKACNPSNDQCCKSSKLVCSQKTRWCKYQI* * & 4074.97 \\
\hline$H w T X-I V \quad E^{1} G / E^{4} G / K^{18} \mathrm{~A}$ & GCLGIFKACNPSNDQCCASSKLVCSRKTRWCKYQI * & 3902.85 \\
\hline $\mathrm{HWTx}-\mathrm{IV} \mathrm{E}^{4} \mathrm{~K} / \mathrm{R}^{26} \mathrm{~A} / \mathrm{Y}^{33} \mathrm{~W}$ & ECLKIFKACNPSNDQCCKSSKLVCSAKTRWCKWQI* & 4040.97 \\
\hline $\mathrm{HwTx}-\mathrm{IV} \mathrm{C}_{\mathrm{ter}} \mathrm{COOH}$ & ECLEIFKACNPSNDQCCKSSKLVCSRKTRWCKYQI-COOH & 4104.93 \\
\hline $\mathrm{HwTx}-\mathrm{IV} \mathrm{K}^{36} / \mathrm{C}_{\text {ter }} \mathrm{COOH}$ & ECLEIFKACNPSNDQCCKSSKLVCSRKTRWCKYQIK-COOH & 4233.03 \\
\hline $\mathrm{HwTx}-\mathrm{IV} \mathrm{E}^{4} \mathrm{~K} / \mathrm{C}_{\text {ter }} \mathrm{COOH}$ & ECLKIFKACNPSNDQCCKSSKLVCSRKTRWCKYQI-COOH & 4103.99 \\
\hline $\mathrm{HwTX}-\mathrm{IV} \mathrm{E}^{4} \mathrm{G} / \mathrm{C}_{\mathrm{ter}} \mathrm{COOH}$ & ECLGIFKACNPSNDQCCKSSKLVCSRKTRWCKYQI-COOH & 4032.91 \\
\hline
\end{tabular}

FIGURE 1 | Sequence alignment, with the disulfide bond connectivity, and molecular masses of HwTx-IV and its 19 analogues. The residue substitutions in the peptide analogues are indicated in red. WT: Wild-type. MM: Molecular masses after folding/oxidation. *: C-terminal amidation.

\section{MATERIALS AND METHODS}

\section{Chemical Synthesis of HwTx-IV Analogues}

HwTx-IV analogues were all chemically assembled and provided by Smartox Biotechnology. Briefly, assembly was done stepwise on 2-chlorotrityl chloride polystyrene resin at a $0.05 \mathrm{mmol}$ or $0.1 \mathrm{mmol}$ scale, using Fmoc-based Solid Phase Peptide Synthesis (SPPS) on a PTI Symphony synthesizer. $20 \%$ piperidine in DMF was used to remove the Fmoc protecting group and free amine was coupled using tenfold excess of Fmoc amino acids and HCTU/DIEA activation in NMP/DMF $(3 \times 15$ min $)$. Peptide de-protections and cleavages from the resin were done with TFA/ $\mathrm{H}_{2} \mathrm{O} / 1,3$-dimethoxybenzene (DMB)/TIS/2,2' -(Ethylenedioxy) diethanethiol (DODT) 85.1/5/2.5/3.7/3.7 (vol.). They were then precipitated with cold diethyl ether. Oxidative folding of the crude linear peptides were successfully conducted at RT in the conditions optimized for HwTx-IV using a peptide concentration of $0.1 \mathrm{mg} / \mathrm{ml}$ in a $0.1 \mathrm{M}$ Tris buffer at $\mathrm{pH} 8.0$ containing $10 \%$ of DMSO. The amino acid sequences of HwTx-IV and its 19 analogues are shown in Figure 1, along with the molecular masses after folding/oxidation.

\section{Cell Cultures}

$\mathrm{CHO}$ cells stably expressing the $\mathrm{hNa}_{\mathrm{V}} 1.7$ channel subtype were cultured in Dulbecco's Modified Eagle's Medium F-12 (DMEM/ F12) supplemented with $10 \%$ fetal bovine serum, $2 \mathrm{mM}$ glutamine, $200 \mu \mathrm{g} / \mathrm{ml}$ hygromycine $\mathrm{B}, 10 \mathrm{U} / \mathrm{ml}$ penicillin and $10 \mu \mathrm{g} / \mathrm{ml}$ streptomycin (Gibco, Grand Island, NY). HEK-293 cells stably expressing the $\mathrm{hNa}_{\mathrm{V}} 1.6$ channel subtype were cultured in Dulbecco's Modified Eagle's Medium (DMEM) supplemented with $10 \%$ fetal calf serum, $1 \mathrm{mM}$ pyruvic acid, $4.5 \mathrm{~g} / \mathrm{L}$ glucose,
$2 \mathrm{mM}$ glutamine, $800 \mu \mathrm{g} / \mathrm{ml} \mathrm{G} 418,10 \mathrm{U} / \mathrm{ml}$ penicillin and $10 \mu \mathrm{g} /$ $\mathrm{ml}$ streptomycin (Gibco, Grand Island, NY). All cell lines were incubated at $37^{\circ} \mathrm{C}$ in a $5 \% \quad \mathrm{CO}_{2}$ atmosphere. For electrophysiological recordings, cells were detached with trypsin, and floating single cells were diluted ( 300,000 cells/ $\mathrm{ml}$ ) in an extracellular solution containing (in $\mathrm{mM}$ ): $140 \mathrm{NaCl}, 4$ $\mathrm{KCl}, 2 \mathrm{CaCl}_{2}, 1 \mathrm{MgCl}_{2}, 5$ glucose and $10 \mathrm{HEPES}(\mathrm{pH} 7.4$, osmolarity 298 mOsm), that was used throughout the experiments.

\section{Pharmacological Applications Using the Automated Patch-Clamp System}

HwTx-IV analogues were investigated on $\mathrm{CHO}$ cells expressing $\mathrm{hNa}_{\mathrm{v}} 1.7$ channel and HEK-293 cells expressing $\mathrm{hNa}_{\mathrm{V}} 1.6$ channel using the automated patch-clamp system from Nanion (SyncroPatch 384 PE; München, Germany). Chips with singlehole and high-resistance ( 6-7 M $\Omega$ ) were used for both cell lines. Voltage pulses and whole-cell recordings were achieved using the PatchControl384 v1.5.2 software (Nanion) and the Biomek v1.0 interface (Beckman Coulter). Prior to recordings, dissociated cells were shaken at $200 \mathrm{RPM}$ in a cell hotel reservoir at $10^{\circ} \mathrm{C}$. After cell catching, sealing, whole-cell formation, liquid application, recording, and data acquisition were all performed sequentially and automatically. The intracellular solution contained (in $\mathrm{mM}$ ): $110 \mathrm{CsF}, 10 \mathrm{CsCl}, 10 \mathrm{NaCl}, 1 \mathrm{MgCl}_{2}, 1 \mathrm{CaCl}_{2}, 10 \mathrm{EGTA}$ and 10 HEPES ( $\mathrm{pH} 7.2$, osmolarity $280 \mathrm{mOsm}$ ), and the extracellular solution was as described above. Whole-cell experiments were done at $-100 \mathrm{mV}$ holding potential and at room temperature $\left(18-22^{\circ} \mathrm{C}\right)$, while currents triggered at either -10 or $0 \mathrm{mV}$ test potential were sampled at $20 \mathrm{kHz}$. Stimulation frequency was set 
at $0.2 \mathrm{~Hz}$. Each HwTx-IV analogue was prepared at various concentrations in the extracellular solution, itself supplemented with $0.3 \%$ of bovine serum albumin (BSA), also added in the control solution. The peptides were distributed in 384-well microplates according to the number of compounds to be tested (generally four), the concentration range defined from the $\mathrm{IC}_{50}$ of wild-type HwTx-IV, and the number of cells desired for each experimental condition. Compound solutions were diluted 3 times in the patch-clamp recording well by adding 30-60 $\mu \mathrm{l}$ external solution, to reach the final reported concentration and the test volume of $90 \mu \mathrm{l}$. For establishing dose-response curves, the compounds were tested at a test potential of either -10 or $0 \mathrm{mV}$ for $50 \mathrm{~ms}$ with a pulse every $5 \mathrm{~s}$. Percentages of current inhibition were measured at steadystate of blockage or at the end of a 15-min application time.

\section{Docking of Toxin Analogues Onto $\mathrm{hNa}$ 1.7 Channel Structure}

Based on the $\mathrm{hNa}_{\mathrm{V}} 1.7 \mathrm{VSD} 2-\mathrm{Na}_{\mathrm{V}} \mathrm{Ab}$ chimera channel structure, obtained by cryo-electron microscopy (PDB: 6N4R), and the 3D solution structure of HwTx-IV (PDB code 1MB6), obtained by 2D ${ }^{1} \mathrm{H}$-NMR, wild-type amidated or carboxylated HwTx-IV was docked using ZDOCK v.3.0.2. Docking was used because the CryoEM structures reported in the literature lack the HwTx-IV structure in the referred PDB code (6J8G or 6J8H) (Shen et al., 2019) or because the region of interaction is not resolved according to the PDB code (6W6O) (Gao et al., 2020). Also, the earlier docking models, reported after crosslinking experiments, were not publicly available (Tzakoniati et al., 2020). Residues previously reported as implicated in HwTx-IV/hNa 1.7 VSD2 channel interaction $\left(\mathrm{T}^{518}\right.$ $\mathrm{F}^{761}$ and $\mathrm{S}^{807}-\mathrm{E}^{817}$ on $\mathrm{hNa} \mathrm{V}_{\mathrm{V}} 1.7 \mathrm{VSD} 2$ and $\mathrm{S}^{25}-\mathrm{I}^{35}$ on HwTx-IV) have been used to guide docking. Only $\mathrm{K}^{32}$ of HwTx-IV has been selected as a conserved binding site residue for all analogues. Interactions between HwTx-IV and $\mathrm{hNa}_{\mathrm{V}} 1.7$ VSD2 amino acids have been analyzed using Discovery Studio (Dassault System Biovia) and the resulting 3D structures were drawn with the PyMOL software (The PyMOL Molecular Graphics System, v.2.0 Schrödinger, LLC).

\section{RESULTS}

\section{Chemical Syntheses of HwTx-IV Analogues}

Overall, nineteen analogues were successfully chemically synthesized using fmoc solid-phase peptide chemistry. Proper folding and oxidation of the peptides were evaluated by checking the correspondence between theoretical versus experimental masses as assessed by mass spectrometry (Figure 1). Ten analogues with single amino acid substitution were produced, followed by three analogues with double amino acid substitutions, two analogues with triple amino acid substitutions, and four analogues with modifications at the C-terminus. It was remarkable that none of the analogues posed problems for the folding of the peptide (RP-HPLC data and yield calculations, not shown) in spite of the fact that this peptide folds according to an ICK motif and that some analogues harbor up to three substitutions.

\section{Single Amino Acid-Substituted HwTx-IV Analogues Affecting Peptide Potency Onto hNav1.7}

Some of the earlier SAR investigations were performed with recombinant HwTx-IV peptides that are lacking C-terminal amidation (Minassian et al., 2013; Sermadiras et al., 2013; Rahnama et al., 2017; Neff et al., 2020), an amidation that is however crucial for potency onto $\mathrm{hNa}_{\mathrm{V}} 1.7$ (Revell et al., 2013). Also, in some of these reports, several recombinant analogues carried additional residues at either the $\mathrm{N}$ - or the $\mathrm{C}$-terminus, all susceptible to affect peptide potency (Minassian et al., 2013; Sermadiras et al., 2013; Neff et al., 2020). Therefore, some analogues that were deemed of interest were tested herein on $\mathrm{hNa}_{\mathrm{V}} 1.7$ to confirm or infirm earlier reports in more standardized conditions (normal C-terminal amidation and absence of extranon-native amino acid residues).

As shown in Figure 2A, we identified 3 analogues of HwTx-IV with mono-substituted amino acid residues (HwTx-IV E ${ }^{1} \mathrm{G}, \mathrm{HwTx}$ IV $E^{4} \mathrm{G}$, and $\mathrm{HwTx}-\mathrm{IV} \mathrm{K}^{18} \mathrm{~A}$ ) that possessed better potency towards the $\mathrm{hNa}_{\mathrm{V}} 1.7$ channel subtype. This was best exemplified by current traces illustrating the percentage of inhibition of $\mathrm{Na}^{+}$inward current at $10 \mathrm{nM}$ peptide analogue (upper panel). One substitution brings in a remarkable improvement in HwTx-IX potency onto $\mathrm{hNa}_{\mathrm{V}} 1.7$ : the $\mathrm{E}^{4} \mathrm{G}$ mutation with an $\mathrm{IC}_{50}$ value which is 6.2 -fold better than wildtype HwTx-IV (Figure 2B). The improvements made by the $\mathrm{E}^{1} \mathrm{G}$ or the $\mathrm{K}^{18} \mathrm{~A}$ mutations were milder. All other mono-substituted analogues of HwTx-IV had decreased potencies towards $\mathrm{hNa}_{\mathrm{V}} 1.7$ with most of them producing almost no inhibition at all at $10 \mathrm{nM}$ (Figure 2A). As shown by the average dose-response curves, the $\mathrm{E}^{4} \mathrm{~K}$ mutation was most conservative, followed by the $\mathrm{Y}^{33} \mathrm{~W}$ one. As expected from earlier reports (see Discussion section), the most disruptive single point mutation was $\mathrm{K}^{32} \mathrm{~N}$, while $R^{26} \mathrm{~A}, R^{26} \mathrm{Q}$ and $\mathrm{T}^{28} \mathrm{~W}$ had milder effects on the HwTx-IV loss of potency (Figure 2C and Table $\mathbf{1}$ ).

\section{Single Amino Acid-Substituted HwTx-IV Analogues Affecting Peptide Potency Onto hNav1.6}

We next tested wild-type HwTx-IV along with its nine monosubstituted amino acid analogues onto the $\mathrm{Na}^{+}$current carried by $\mathrm{hNa}_{\mathrm{V}} 1.6$ subtype. We used a concentration of $100 \mathrm{nM}$ to evaluate which analogue performed better than the wild-type HwTx-IV on $\mathrm{Na}^{+}$current inhibition. As shown in Figure 3A, $100 \mathrm{nM}$ of HwTxIV inhibits less than $50 \%$ of $\mathrm{hNa}_{\mathrm{V}} 1.6$ current, which is coherent with the average $\mathrm{IC}_{50}$ value of $226.6 \mathrm{nM}$ (Figure 3B). As such, natively, without any sequence alteration, HwTx-IV is 22.9-fold more potent on $\mathrm{hNa}_{\mathrm{V}} 1.7$ than on $\mathrm{hNa}_{\mathrm{V}} 1.6$ channel subtype (starting selectivity ratio as detailed in Figure 4). Five out of nine mono-substituted amino acid analogues displayed better potency on $\mathrm{hNa}_{\mathrm{V}} 1.6$ than wild-type HwTx-IV itself: HwTx-IV E ${ }^{1}$ G (3.6-fold better), HwTxIV E ${ }^{4} \mathrm{G}$ (36-fold better), HwTx-IV E ${ }^{4} \mathrm{~K}$ (10.8-fold better), HwTx-IV $\mathrm{E}^{4} \mathrm{R}$ (20.4-fold better) and HwTx-IV $\mathrm{Y}^{33} \mathrm{~W}$ (1.1-fold better).

In contrast, 4 mono-substituted analogues of HwTx-IV displayed lower potencies for $\mathrm{hNa}_{\mathrm{V}} 1.6$ compared to wildtype HwTx-IV. Two analogues still affected $\mathrm{hNa}_{\mathrm{V}} 1.6$ with 

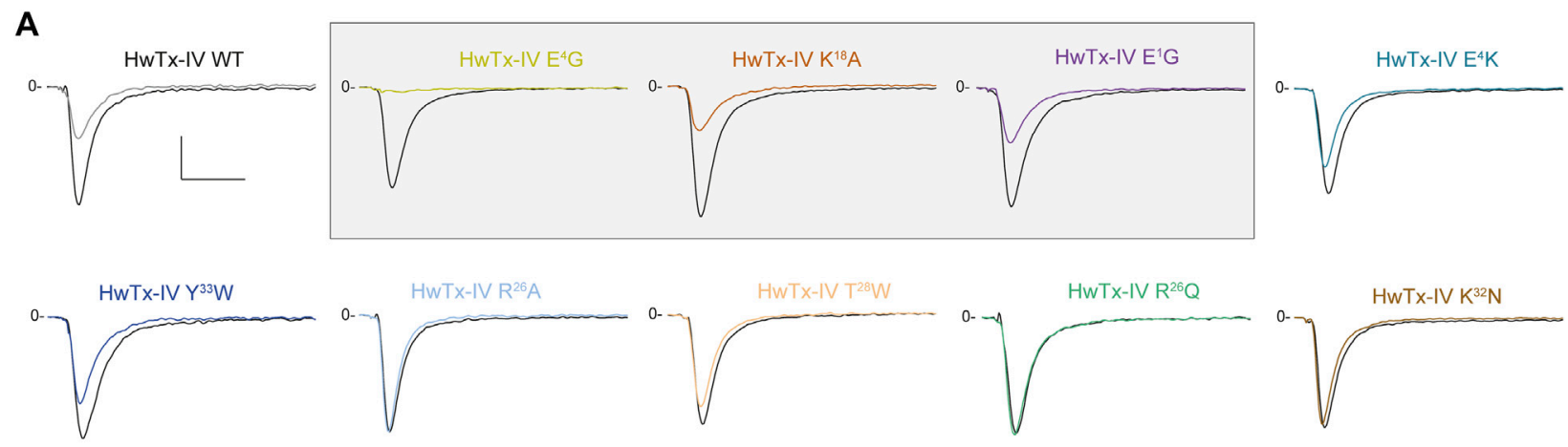

B

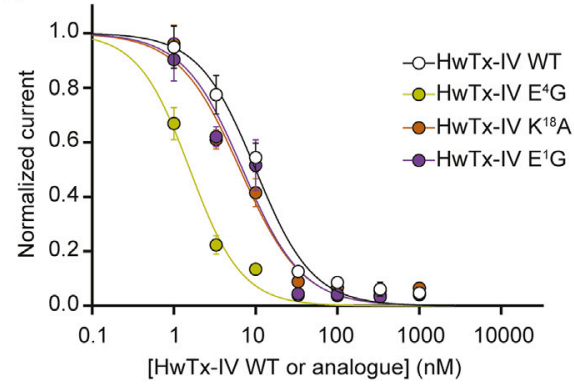

C

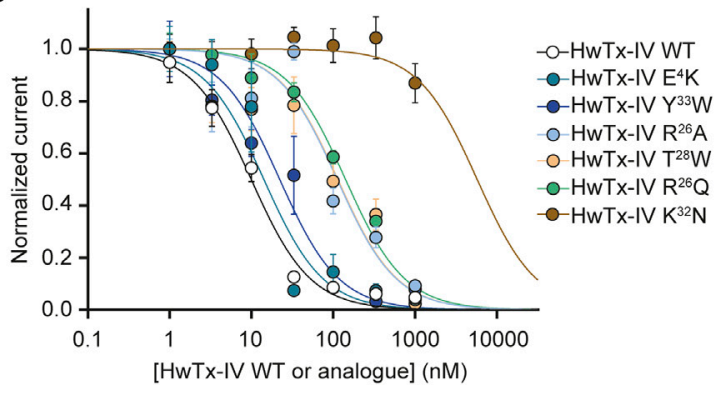

FIGURE 2 | Effects of HWTx-IV and its nine mono-substituted amino acid analogues on CHO cells stably expressing the hNav1.7 channel subtype. (A) Representative traces of current flowing through the hNav1.7 subtype, recorded before (black traces) and after (coloured traces) exposure to $10 \mathrm{nM}$ of the indicated peptide. Vertical and horizontal scales (applied to all traces) are $0.5 \mathrm{nA}$ and $5 \mathrm{~ms}$, respectively. The mono-substituted amino acid analogues more potent than HwTx-IV are highlighted by a grey rectangle. (B) and (C) Concentration-response curves of the effects of HwTx-IV (white circles) and analogues (coloured circles) on hNav1.7 peak current, recorded during a $-10 \mathrm{mV}$ test pulse voltage. Each value, expressed relatively to that obtained before peptide application, represents the mean \pm S.E.M. of data obtained from 2-8 cells. The theoretical curves correspond to data point fits with the mean $\mathrm{IC}_{50}$ values indicated in Table $\mathbf{1}$.

TABLE 1 | Mean \pm S.E.M. of $\mathrm{IC}_{50}$ values ( $\mathrm{n}$ cells) determined from the concentration-response curves of the effects of wild-type (WT) HwTX-IV and analogues on $\mathrm{hNa}$ 1. 7 and hNav1.6 peak currents.

\begin{tabular}{|c|c|c|c|c|c|c|c|c|}
\hline & \multicolumn{4}{|c|}{$h N a_{v} 1.7$} & \multicolumn{4}{|c|}{$\mathrm{hNa} \mathrm{v}_{\mathrm{v}} \mathbf{1 . 6}$} \\
\hline & Mean $\mathrm{IC}_{50}(\mathrm{nM})$ & SE.M. & $\mathbf{n}$ & versus WT & Mean $\mathrm{IC}_{50}(\mathrm{nM})$ & SE.M. & $\mathbf{n}$ & versus WT \\
\hline HwTx-IV WT & 9.9 & 1.1 & $5-7$ & 1.00 & 226.6 & 1.2 & $6-10$ & 1.00 \\
\hline HwTx-IV E ${ }^{1} G$ & 6.9 & 1.1 & $3-7$ & 0.70 & 62.4 & 1.2 & $4-7$ & 0.28 \\
\hline HwTx-IV E ${ }^{4} G$ & 1.6 & 1.1 & $6-7$ & 0.16 & 6.3 & 1.3 & 3 & 0.03 \\
\hline HwTx-IV E ${ }^{4} K$ & 14.2 & 1.2 & $2-8$ & 1.43 & 20.9 & 1.3 & 3 & 0.09 \\
\hline HwTx-IV E ${ }^{4} R$ & - & - & - & - & 11.1 & 1.3 & $3-5$ & 0.05 \\
\hline HwTx-IV K ${ }^{18} A$ & 6.4 & 1.1 & $3-7$ & 0.65 & 416.2 & 1.3 & $3-7$ & 1.84 \\
\hline HwTX-IV K K ${ }^{32} N$ & 5752.0 & 1.6 & $4-7$ & 581 & $>1,000$ & - & $2-7$ & $>4.4$ \\
\hline HwTx-IV $R^{26} \mathrm{~A}$ & 111.7 & 1.2 & $4-7$ & 11.28 & 614.2 & 1.2 & $3-6$ & 2.71 \\
\hline HwTx-IV $R^{26} Q$ & 141.4 & 1.1 & $3-5$ & 14.28 & $>1,000$ & - & $2-8$ & $>4.4$ \\
\hline HwTx-IV T ${ }^{28} W$ & 114.1 & 1.2 & $4-6$ & 11.53 & - & - & - & - \\
\hline HwTx-IV $Y^{33} W$ & 22.2 & 1.2 & $3-7$ & 2.24 & 207.2 & 1.3 & $3-9$ & 0.91 \\
\hline HwTx-IV E ${ }^{1} G / E^{4} G$ & 2.0 & 1.1 & $3-7$ & 0.20 & 3.7 & 1.2 & $1-2$ & 0.02 \\
\hline HwTx-IV E ${ }^{4} R / K^{32} N$ & $>1,000$ & - & $2-8$ & $>101$ & $>333$ & - & $2-3$ & $>1.5$ \\
\hline HwTx-IV E $E^{4} K / R^{26} Q$ & 3.6 & 1.1 & $2-8$ & 0.36 & 3.4 & 1.5 & 5 & 0.02 \\
\hline$H w T x-I V E^{1} G / E^{4} G / K^{18} A$ & 0.8 & 1.1 & $3-7$ & 0.08 & 4.9 & 1.2 & 4 & 0.02 \\
\hline HwTX-IV E ${ }^{4} \mathrm{~K} / R^{26} \mathrm{AV}^{33} \mathrm{~W}$ & 0.9 & 1.1 & $3-8$ & 0.09 & 86.4 & 1.4 & 5 & 0.38 \\
\hline $\mathrm{HwTx}-\mathrm{IV} \mathrm{C}_{\mathrm{ter}} \mathrm{COOH}$ & 176.3 & 1.1 & $5-8$ & 17.81 & $1,230.0$ & 1.3 & $2-6$ & 5.43 \\
\hline $\mathrm{HwTx}$-IV K $\mathrm{K}^{36} / \mathrm{C}_{\text {ter }} \mathrm{COOH}$ & 29.0 & 1.2 & $2-6$ & 2.93 & $1,334.0$ & 1.6 & $2-7$ & 5.89 \\
\hline $\mathrm{HwTx}$-IV E ${ }^{4} \mathrm{~K} / \mathrm{C}_{\text {ter }} \mathrm{COOH}$ & 11.9 & 1.1 & $4-7$ & 1.20 & 135.7 & 1.3 & $4-10$ & 0.60 \\
\hline $\mathrm{HwTx}$-IV E ${ }^{4} \mathrm{G} / \mathrm{C}_{\text {ter }} \mathrm{COOH}$ & 14.9 & 1.1 & $2-7$ & 1.51 & 55.1 & 1.2 & $5-10$ & 0.24 \\
\hline
\end{tabular}

Bold value highlight the wild-type peptide for a better comparison with analogues. 

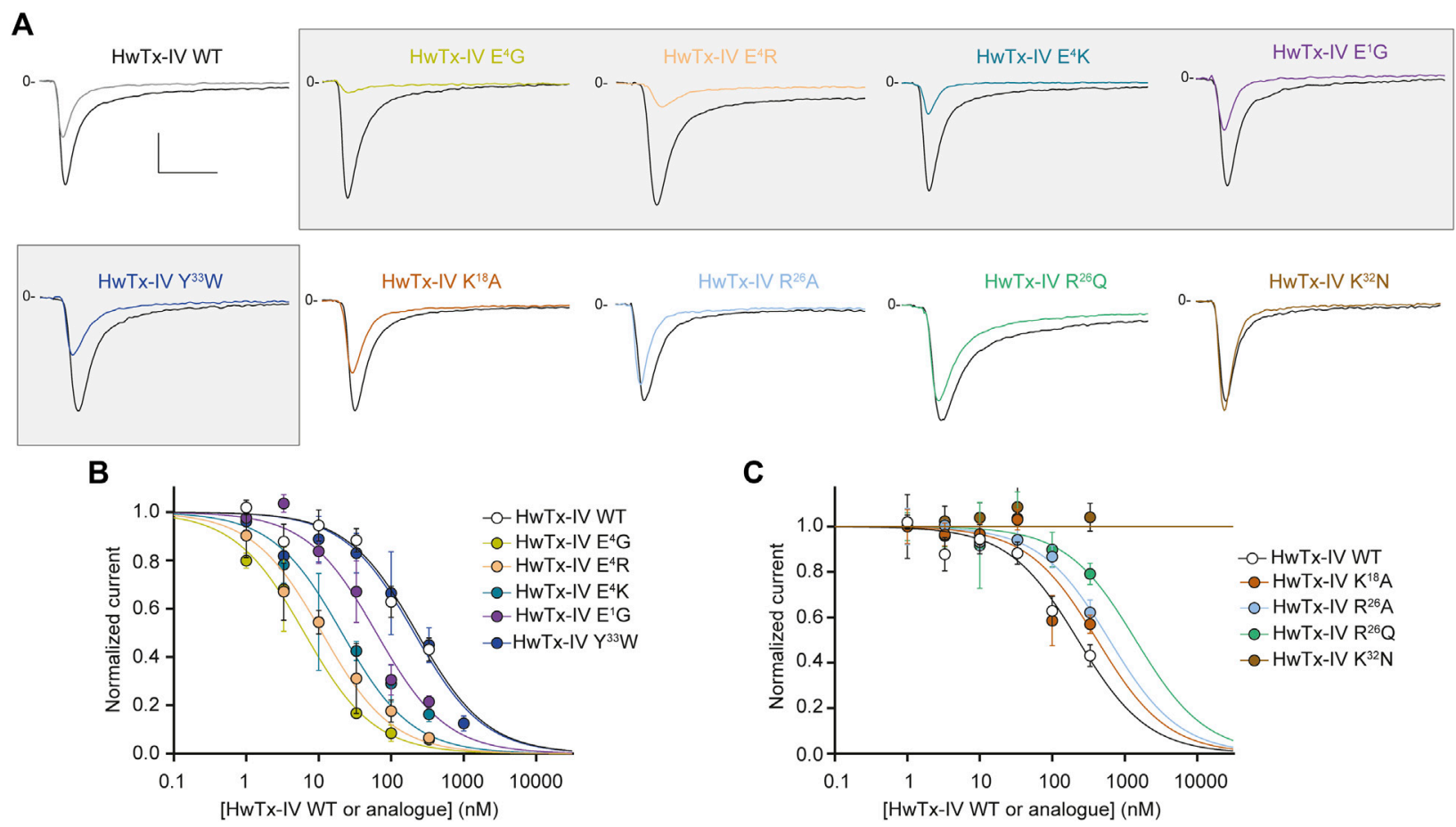

FIGURE 3 | Effects of HwTX-IV and its nine mono-substituted amino acid analogues on HEK-293 cells stably expressing the hNav1.6 channel subtype. (A) Representative traces of current flowing through the hNav1.6 subtype, recorded before (black traces) and after (coloured traces) exposure to $100 \mathrm{nM}$ of the indicated peptide. Vertical and horizontal scales (applied to all traces) are $0.5 \mathrm{nA}$ and $5 \mathrm{~ms}$, respectively. The mono-substituted amino acid analogues more potent than HwTx-IV are highlighted by grey rectangles. (B) and (C) Concentration-response curves of the effects of HwTx-IV (white circles) and analogues (coloured circles) on hNav1.6 peak current, recorded during a 0-mV test-pulse voltage. Each value, expressed relatively to that obtained before peptide application, represents the mean \pm S.E.M. of data obtained from 2-10 cells. The theoretical curves correspond to data point fits with the mean $\mathrm{IC}_{50}$ values indicated in Table $\mathbf{1}$.

A

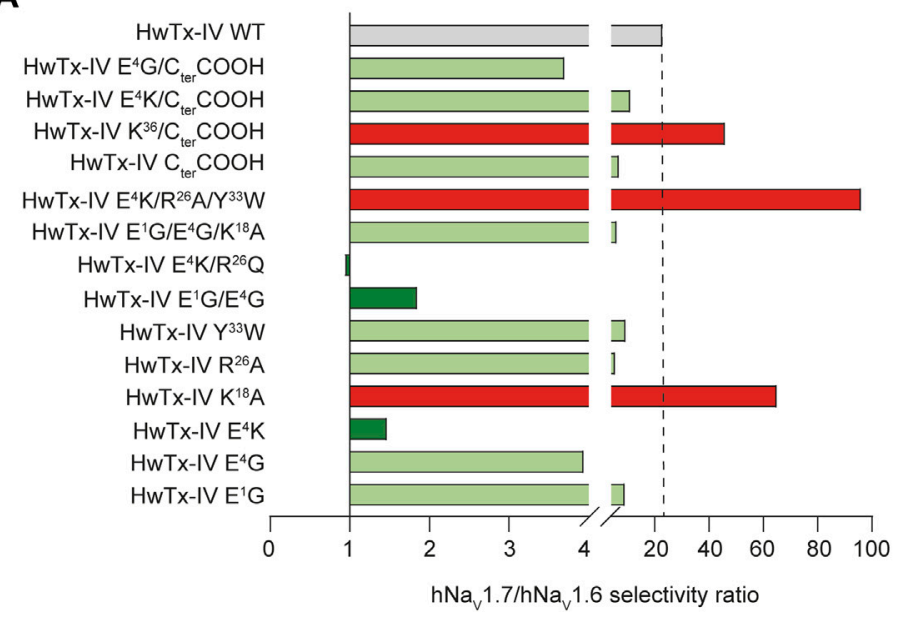

B

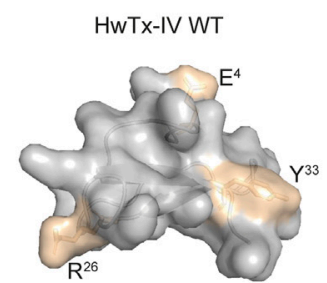

FIGURE 4 | Effects of HwTx-IV and analogues on the hNav1.7/hNav1.6 selectivity ratio. (A) Histogram of hNav1.7/hNav1.6 selectivity ratio of HwTx-IV and analogues (dashed line: reference value for HWTx-IV WT; ratio $>$ WT value in red and ratio $<$ WT value in green), determined from the inverse ratio of their respective $\mathrm{IC}_{50}$ mean values indicated in Table 1. (B) Structural representation of two analogues compared to HwTx-IVWT: HWTx-IV E ${ }^{4} \mathrm{~K} / R^{26} \mathrm{Q}$ for selectivity ratio close to 1 , and HWTXIV E ${ }^{4} \mathrm{~K} / R^{26} \mathrm{~A} \mathrm{Y}^{33} \mathrm{~W}$ for enhanced selectivity ratio.

measurable potency: $\mathrm{HwTx}$-IV $\mathrm{K}^{18} \mathrm{~A}$ (1.8-fold reduction) and HwTx-IV $R^{26} \mathrm{~A}$ (2.7-fold reduction). The two other analogues have a too significant shift in $\mathrm{IC}_{50}$ values to be measured
(HwTx-IV $\mathrm{K}^{32} \mathrm{~N}$ and HwTx-IV $R^{26} \mathrm{Q}$, both $>1 \mu \mathrm{M}$ ). In conclusion, among mono-substituted HwTx-IV analogues, the most interesting ones are those with a sequence 
A

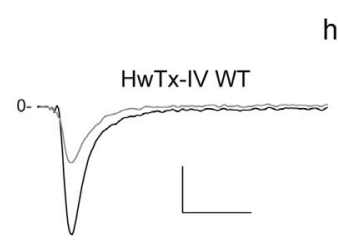

$\mathrm{hNa}_{\mathrm{v}} 1.7$
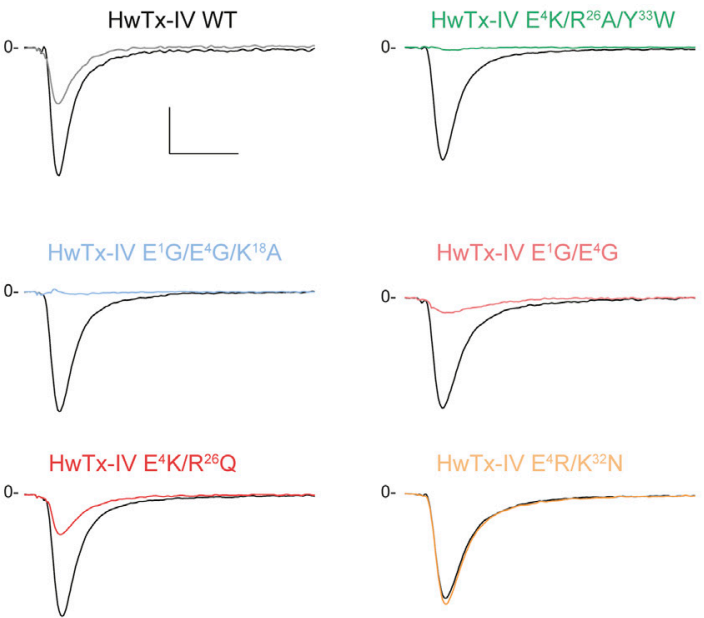

B

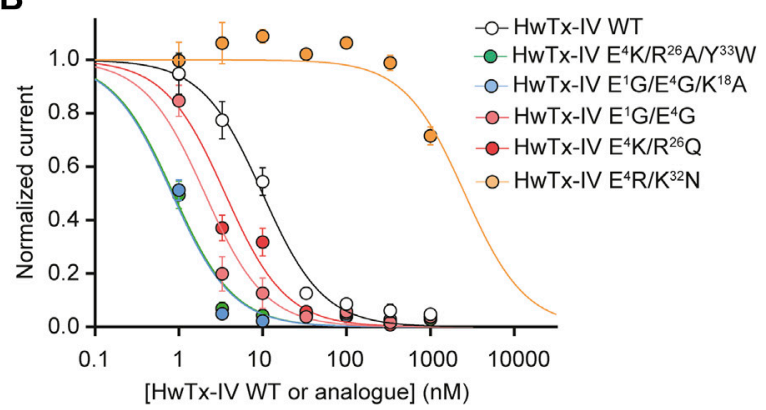

C $\mathrm{hNa}_{\mathrm{v}} 1.6$
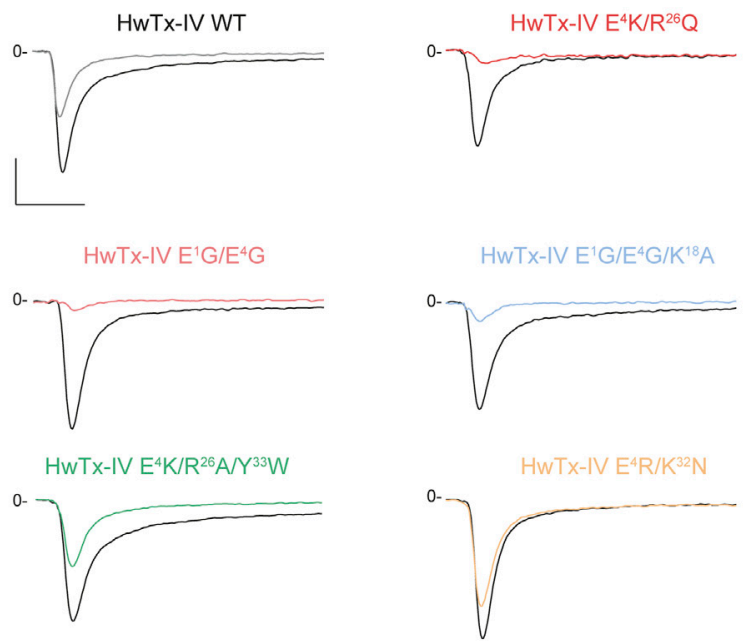

D

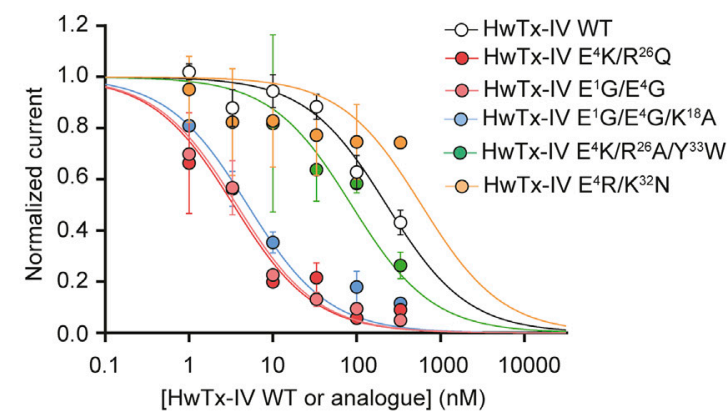

FIGURE 5 | Effects of HwTX-IV and its five double- or triple-substituted amino acid analogues on CHO and HEK-293 cells stably expressing the hNav1.7 (A,B) and hNav1.6 (C,D) channel subtypes, respectively. (A) and (C) Representative traces of current flowing through the hNav1.7 (A) or hNav1.6 (C) subtype, recorded before (black traces) and after (coloured traces) exposure to $10 \mathrm{nM}(\mathrm{A})$ or $100 \mathrm{nM}(\mathrm{C})$ of the indicated peptide. Vertical and horizontal scales (applied to all traces) are $0.5 \mathrm{nA}$ and $5 \mathrm{~ms}$, respectively. (B) and (D) Concentration-response curves of the effects of HwTX-IV (white circles) and analogues (coloured circles) on hNav1.7 (B) and hNav1.6 (D) peak currents, recorded during $-10-\mathrm{mV}$ and 0-mV test-pulse voltages, respectively. Each value, expressed relatively to that obtained before peptide application, represents the mean \pm S.E.M. of data obtained from 1-8 cells. The theoretical curves correspond to data point fits with the mean $I C_{50}$ values indicated in Table $\mathbf{1}$.

alteration at position $4\left(\mathrm{HwTx}-\mathrm{IV} \mathrm{E}^{4} \mathrm{G}\right.$ or $\left.\mathrm{HwTx}-\mathrm{IV} \mathrm{E}^{4} \mathrm{~K}\right)$ or 18 $\left(\mathrm{HwTx}-\mathrm{IV} \mathrm{K}^{18} \mathrm{~A}\right)$ since these analogues led to an improved potency for $\mathrm{hNa}_{\mathrm{V}} 1.7$ (Figure 4 and Table 1). This improved potency of HwTx-IV $\mathrm{K}^{18} \mathrm{~A}$ was associated to an improved selectivity versus $\mathrm{hNa}_{\mathrm{V}} 1.6$, which is likely to reduce the molecule side effects resulting from impairment of neuromuscular transmission. In contrast, HwTx-IV $E^{4} G$ and HwTx-IV $E^{4} K$ tended clearly to abolish differences between potencies for $\mathrm{hNa}_{\mathrm{V}} 1.7$ and $\mathrm{hNa}_{\mathrm{V}} 1.6$, allowing to produce pan- $\mathrm{Na}_{\mathrm{V}}$ blockers.

\section{Combining Several Substitutions Onto HwTx-IV May Also Bring Competitive Advantages in Improving hNav1.7/hNav1.6 Selectivity Ratio}

We first attempted to combine two or three substitutions that individually were shown to be beneficial for the potency of HwTxIV onto $h \mathrm{Na}_{\mathrm{V}} 1.7\left(\mathrm{E}^{1} \mathrm{G}, \mathrm{E}^{4} \mathrm{G}, \mathrm{K}^{18} \mathrm{~A}\right)$ or $\mathrm{hNa}_{\mathrm{V}} 1.6\left(\mathrm{E}^{1} \mathrm{G}, \mathrm{E}^{4} \mathrm{G}\right.$ ) (Figures 2A, Figure 3A). The double mutant HwTx-IV $E^{1} G / E^{4} G$ produced
$\mathrm{IC}_{50}$ values of $2.0 \pm 1.1 \mathrm{nM}$ for $\mathrm{hNa}_{\mathrm{V}} 1.7$ (Figure $5 \mathbf{A}$ ) and $3.7 \pm 1.2 \mathrm{nM}$ for $\mathrm{hNa}_{\mathrm{V}} 1.6$ (Figure 5B). These values are more or less similar to those brought by the single $\mathrm{E}^{4} \mathrm{G}$ substitution, but with a slight improvement introduced by the additional $\mathrm{E}^{1} \mathrm{G}$ mutation in the case of the $\mathrm{hNa} \mathrm{V}_{\mathrm{V}} 1.6$ subtype. Adding the $\mathrm{K}^{18} \mathrm{~A}$ substitution onto the HwTx-IV $\mathrm{E}^{1} \mathrm{G} / \mathrm{E}^{4} \mathrm{G}$ mutant (HwTx-IV $\mathrm{E}^{1} \mathrm{G} / \mathrm{E}^{4} \mathrm{G} / \mathrm{K}^{18} \mathrm{~A}$ ) did not result in a marked benefit of the peptide potency onto both targets (Figure 5). This was expected since the effect of $\mathrm{K}^{18} \mathrm{~A}$ substitution was similar to that of the $\mathrm{E}^{1} \mathrm{G}$ substitution and 4-fold lower to that of the $E^{4} G$ substitution on the $h \mathrm{ha}_{\mathrm{V}} 1.7$ subtype. In contrast to the $\mathrm{E}^{1} \mathrm{G}$ and $\mathrm{E}^{4} \mathrm{G}$ substitutions, it did not, by itself, drastically change HwTx-IV potency for the $\mathrm{hNa}_{\mathrm{V}} 1.6$ subtype (Figures 2A, 3A and Table 1). In a second attempt, we combined two substitutions that individually were, a priori, not favorable for potency improvements, i.e. $R^{26} \mathrm{Q}$ and $\mathrm{E}^{4} \mathrm{~K}$, although the latter was advantageous for $\mathrm{hNa}_{\mathrm{V}} 1.6$ (Figures 2B, 3).

Nevertheless, the combination of these two substitutions had some logic since they introduce compensatory charge alterations in the whole peptide sequence (loss of negative charge and gain of positive charge at position 4 , the latter being 
A
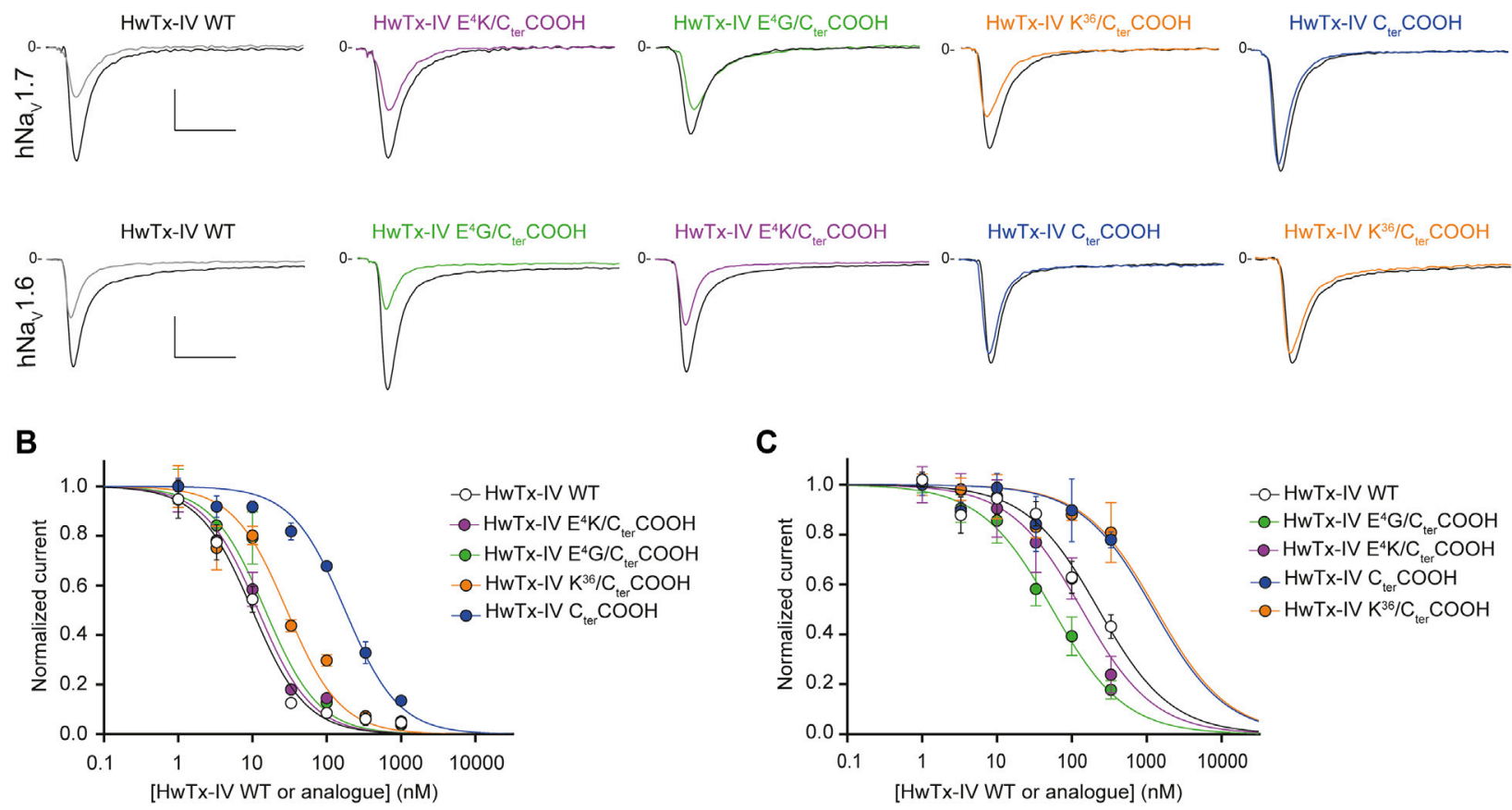

FIGURE 6 | Effects of HwTX-IV and its four C-terminal-altered analogues on $\mathrm{CHO}$ and HEK-293 cells stably expressing the hNa 1.7 and hNa 1.6 channel subtypes, respectively. (A) Representative traces of current flowing through the hNav1.7 (upper traces) or hNav1.6 (lower traces) subtype, recorded before (black traces) and after (coloured traces) exposure to $10 \mathrm{nM}$ (upper traces) or $100 \mathrm{nM}$ (lower traces) of the indicated peptide. Vertical and horizontal scales (applied to all traces) are $0.5 \mathrm{nA}$ and $5 \mathrm{~ms}$ (all traces). (B) and (C) Concentration-response curves of the effects of HwTx-IV (white circles) and analogues (coloured circles) on hNav1.7 (B) and hNav1.6 (C) peak currents, recorded during $-10-\mathrm{mV}$ and $0-\mathrm{mV}$ test-pulse voltages, respectively. Each value, expressed relatively to that obtained before peptide application, represents the mean \pm S.E.M. of data obtained from 1-8 cells. The theoretical curves correspond to data point fits with the mean $I_{50}$ values indicated in $\mathbf{T a b l e}_{\mathbf{1}}$

compensated by the loss of positive charge at position 26). Interestingly, the double mutant $\mathrm{HwTx}-\mathrm{IV} \mathrm{E}^{4} \mathrm{~K} / R^{26} \mathrm{Q}$ yielded excellent potency of the peptide for both channel subtypes (Figure 5). Noteworthy, this double mutation yielded yet another HwTx-IV analogue, along with HwTx-IV $E^{1} G$ and HwTx-IV $E^{1} G / E^{4} G$, that possesses similar and high potencies (low nanomolar range) for both channel subtypes. Introducing a third substitution at position 33 , which individually was quite neutral for both channel types (Figures 2B, 3A), added to those at positions 4 and 26, did not markedly modify the potency for $\mathrm{hNa}_{\mathrm{V}} 1.7$ but produced a 25.4 -fold decrease of that for $\mathrm{hNa}_{\mathrm{V}} 1.6$ compared to HwTx-IV E ${ }^{4} / R^{26} \mathrm{Q}$ (Figures 4, 5 and Table 1).

We also attempted to produce a charge compensation of the $\mathrm{E}^{4} \mathrm{R}$ mutation, similar to $R^{26} \mathrm{Q}$ in the HwTx-IV $\mathrm{E}^{4} \mathrm{~K} / R^{26} \mathrm{Q}$ analogue, by an analogous $\mathrm{K}^{32} \mathrm{~N}$ mutation. As observed by the $\mathrm{IC}_{50}$ values ( $>333 \mathrm{nM}$ in both cases, Figure 5), this strategy did not work because of the crucial role of $\mathrm{K}^{32}$ in the pharmacophore of HwTx-IV (Minassian et al., 2013; Revell et al., 2013).

\section{Examining the Importance of HwTx-IV C-Terminal Amidation on Peptide Potency for Both $\mathrm{Na}_{\mathrm{v}}$ Subtypes}

We first replaced the C-terminal amidated residue by a carboxylated version of the residue. As shown in Figure 6, the potency of HwTx-IV $\mathrm{C}_{\text {ter }} \mathrm{COOH}$ was significantly reduced on both channel subtypes (by 18 -fold on $\mathrm{hNa}_{\mathrm{V}} 1.7$ and by 5 fold on $\mathrm{hNa}_{\mathrm{V}}$ 1.6). These results confirm an earlier report on the role of amidation in HwTx-IV activity (Revell et al., 2013). It is likely that the consequence of amidation on HwTx-IV potency may be explained by the presence of a positive charge at the $\mathrm{C}$-terminus. Indeed, the potency of $\mathrm{HwTx}-\mathrm{IV} \mathrm{K}^{36} /$ $\mathrm{C}_{\text {ter }} \mathrm{COOH}$, in which the peptide is still carboxylated but integrates an additional $\mathrm{K}$ residue, positively-charged on its side-chain, was greatly improved for the $\mathrm{hNa}_{\mathrm{V}} 1.7$ but not $\mathrm{hNa}_{\mathrm{V}} 1.6$ subtype (Figure 6). Similar results were obtained when $\mathrm{E}^{4}$ was mutated in order to remove the negative charge $\left(E^{4} G\right)$, or to replace the negative charge by a positive one $\left(E^{4} K\right)$ at this position. Hence, these results are reminiscent of those obtained with the deleterious $R^{26}$ mutation that also could rescue HwTx-IV potency by an additional $\mathrm{E}^{4}$ substitution (Figure 5). Considering the distal positioning of $\mathrm{E}^{4}$ relatively to $R^{26}$ or to $\mathrm{C}_{\text {ter }} \mathrm{CONH}_{2}$, the beneficial effect of $\mathrm{E}^{4}$ substitution is likely due to a rebalance in dipole moment.

\section{DISCUSSION}

In this manuscript, our goal was to produce HwTx-IV analogues with increased potencies for $\mathrm{hNa}_{\mathrm{V}} 1.7, \mathrm{hNa}_{\mathrm{V}} 1.6$, or both. Based on previous studies, we examined a number of analogues for which only a few observations were reported. Finding analogues with 


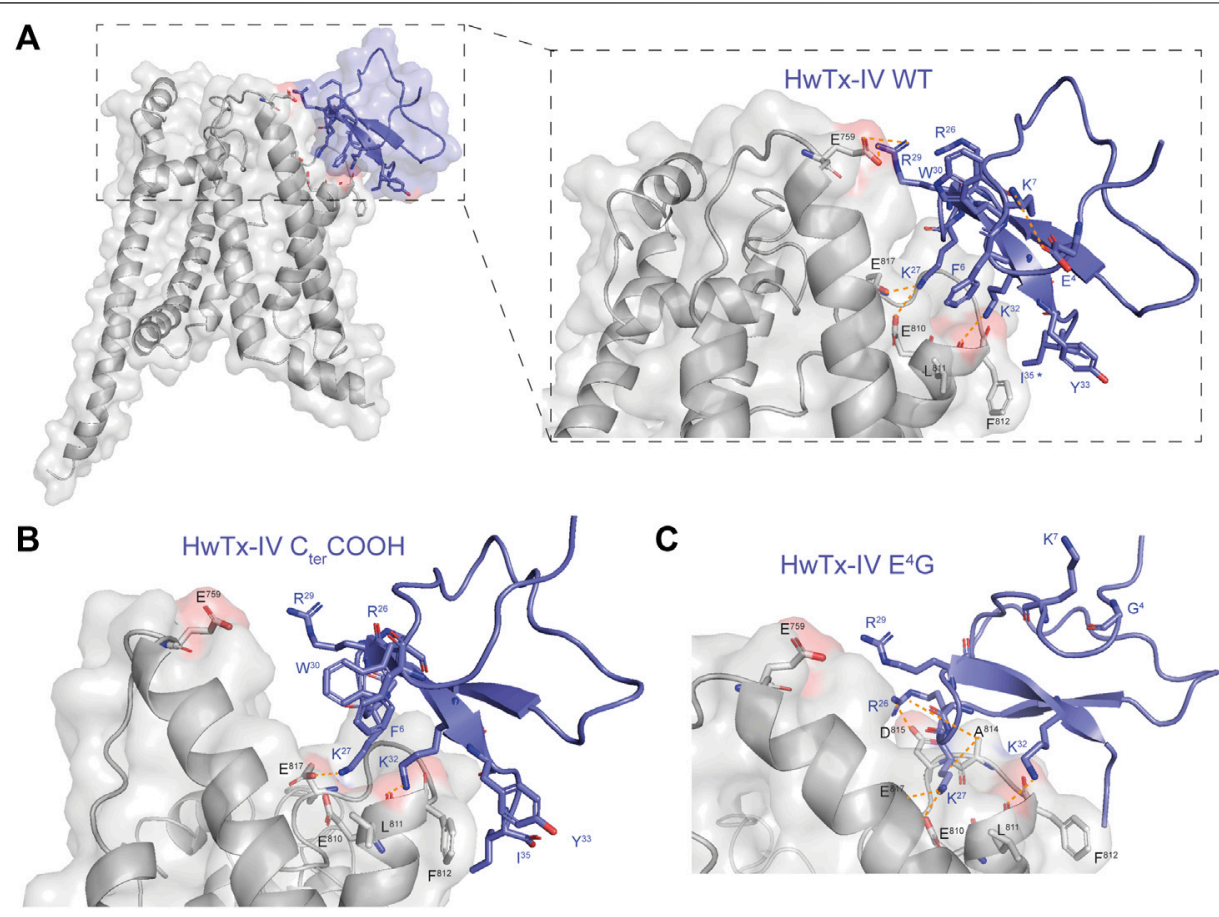

FIGURE 7 | Docking of HwTx-IV analogues on hNav1.7 VSD2-NavAb. (A) Docking of HwTx-IV WT with amidated C-terminal (C contributions of $\mathrm{K}^{27}, R^{29}$ and $\mathrm{K}^{32}$. (B) Docking of the HwTx-IV analogue harboring a carboxylated $\mathrm{C}_{\text {ter }}$ shows loss of interaction through $R^{29}$ and $\mathrm{K}^{27}$ in accordance with a loss of potency. (C) Docking of the HwTx-IV E ${ }^{4} \mathrm{G}$ analogue with its amidated $\mathrm{C}_{\text {ter }}$ shows loss of electrostatic interaction between the residue at position 4 and $\mathrm{K}^{7}$ and larger changes in interactions with VSD2. Residues interacting with VSD2 are shown in sticks. Interactions between HwTx-IV and VSD2 residues are represented by dashed orange lines.

potent activity for $\mathrm{hNa}_{\mathrm{V}} 1.6$ was a particular challenge because the original $\mathrm{hNa}_{\mathrm{V}} 1.7 / \mathrm{hNa}_{\mathrm{V}} 1.6$ selectivity ratio of 23 was largely in favor of $\mathrm{hNa}_{\mathrm{V}}$ 1.7. This endeavor was successful, thanks to mono-, double- or triple-amino acid substitutions. Despite an excellent starting potency for $\mathrm{hNa}_{\mathrm{V}} 1.7$ (mean $\mathrm{IC}_{50}$ value of $9.9 \mathrm{nM}$, in accordance with earlier reports (Xiao et al., 2008; Revell et al., 2013; Sermadiras et al., 2013; Rahnama et al., 2017; Agwa et al., 2020)), it was still possible to further improve the activity of HwTx-IV on this channel subtype by mutations of specific positions, i.e. $\mathrm{E}^{1}, \mathrm{E}^{4}, \mathrm{~K}^{18}, \mathrm{E}^{1} / \mathrm{E}^{4}, \mathrm{E}^{4} / R^{26}, \mathrm{E}^{1} / \mathrm{E}^{4} / \mathrm{K}^{18}$ and $\mathrm{E}^{4} / R^{26} /$ $\mathrm{Y}^{33}$. The maximal optimization factor on potency was 11-12-fold (with the triple mutants $\mathrm{HwTx}-\mathrm{IV} \mathrm{E}^{4} \mathrm{~K} / R^{26} \mathrm{~A} / \mathrm{Y}^{33} \mathrm{~W}$ and $\mathrm{E}^{1} \mathrm{G} /$ $\mathrm{E}^{4} \mathrm{G} / \mathrm{K}^{18} \mathrm{~A}$ ). Concerning $\mathrm{hNa} \mathrm{V}_{\mathrm{V}} 1.6$, the challenge was easier to overcome since the starting potency of HwTx-IV was quite low for this channel subtype (mean $\mathrm{IC}_{50}$ value of $227 \mathrm{nM}$ ). The best analogues were (ranked by decreasing order of improved potency): HwTx-IV $\mathrm{E}^{4} \mathrm{~K} / R^{26} \mathrm{Q}, \mathrm{E}^{1} \mathrm{G} / \mathrm{E}^{4} \mathrm{G}, \mathrm{E}^{1} \mathrm{G} / \mathrm{E}^{4} \mathrm{G} / \mathrm{K}^{18} \mathrm{~A}, \mathrm{E}^{4} \mathrm{G}$, and $\mathrm{E}^{4} \mathrm{R}$, all under or close to $10 \mathrm{nM}$ of $\mathrm{IC}_{50}$ value (improvement by 20 - to 67 -fold), and HwTx-IV $\mathrm{E}^{4} \mathrm{~K}, \mathrm{E}^{1} \mathrm{G}, \mathrm{E}^{4} \mathrm{~K} / R^{26} \mathrm{~A} / \mathrm{Y}^{33} \mathrm{~W}$ and $\mathrm{Y}^{33} \mathrm{~W}$ with less noticeable improvement (by 1.1- to 11-fold). Five analogues had comparable potencies (low nanomolar range) on the two channel subtypes: HwTx-IV $E^{4} G, E^{4} K, E^{1} G / E^{4} G, E^{4} K /$ $R^{26} \mathrm{Q}$ and $\mathrm{E}^{1} \mathrm{G} / \mathrm{E}^{4} \mathrm{G} / \mathrm{K}^{18} \mathrm{~A}$. These data highlight the importance of the type of amino acid at position 4 in obliterating the difference between potencies for the two channel subtypes. However, substitutions at position 4 were not all equipotent since $E^{4} G$ was more potent than $\mathrm{E}^{4} \mathrm{~K}$ on $\mathrm{hNa}_{\mathrm{V}} 1.7$, possibly because $\mathrm{G}^{4}$ was more lipid-friendly than the charged $\mathrm{K}^{4}$, at least for this channel type. With regard to selectivity ratios, two observations can be made: 1) some analogues display a large increased selectivity ratio in favor of $\mathrm{hNa} \mathrm{V}_{\mathrm{V}} 1.7\left(\mathrm{~K}^{18} \mathrm{~A}, \mathrm{E}^{4} \mathrm{~K} / R^{26} \mathrm{~A} / \mathrm{Y}^{33} \mathrm{~W}\right.$ and $\mathrm{K}^{36} / \mathrm{C}_{\text {ter }} \mathrm{COOH}$, all above 46), while keeping excellent apparent affinity on this subtype, and 2) other analogues display a significant reduction in selectivity ratio in favor of $\mathrm{hNa}_{\mathrm{V}} 1.6\left(\mathrm{E}^{4} \mathrm{~K}, \mathrm{E}^{1} \mathrm{G} / \mathrm{E}^{4} \mathrm{G}\right.$ and $\mathrm{E}^{4} \mathrm{~K} /$ $R^{26} \mathrm{Q}$, less than 2) (Figure 4 and Table 1 ).

\section{Fitting Our Data With Earlier Reports}

HwTx-IV has been the focus of several SAR studies, mainly with the aim to improve selectivity for $\mathrm{hNa}_{\mathrm{V}} 1.7$ versus other channel subtypes. Indeed, HwTx-IV suffers from toxicity issues in vivo, most of the symptoms being however related to an action on $\mathrm{Na}_{\mathrm{V}} 1.6$ (Gonçalves et al., 2018b), a subtype that was not the topic of the earlier SAR investigations. In our study, we found HwTxIV to be quite potent on $\mathrm{hNa}_{\mathrm{V}} 1.7$ with a mean $\mathrm{IC}_{50}$ value of $9.9 \mathrm{nM}$, which compares favorably with the literature as far as the peptide was produced chemically (Sermadiras et al., 2013; Neff et al., 2020). Hence, when HwTx-IV was produced according to recombinant approaches, a significant decrease of potency was always observed (Minassian et al., 2013; Sermadiras et al., 2013; Neff et al., 2020). This decrease may be explained by two factors. The first one is simply the absence of C-terminal amidation. Indeed, in our study, the loss of C-terminal amidation results in a 18 -fold decline of potency for $\mathrm{hNa}_{\mathrm{V}} 1.7$ of the chemicallysynthesized peptide (see Figures 6A,B and Table 1). This 
finding is coherent with an earlier report (Revell et al., 2013). According to our docking simulations, this loss of potency should be due to a reduction of the number of interaction points with $\mathrm{hNa}_{\mathrm{V}} 1.7$ (Figure 7). The second one may be due to incomplete or improper folding of the peptide, which is less controlled using recombinant production than chemical synthesis. Indeed, a comparison between the potencies of amidated synthetic and carboxylated recombinant HwTx-IV shows an even more important decline of potency for $\mathrm{hNa}_{\mathrm{V}} 1.7$ in one study (up to 66-fold) (Sermadiras et al., 2013).

Until 2018, to our knowledge, there was no report illustrating the activity of HwTx-IV on $\mathrm{Na}_{\mathrm{V}} 1.6$, a tetrodotoxin (TTX)sensitive channel subtype present in the Ranvier nodes of a-motoneurons (Rahnama et al., 2017). Since then, Gonçalves and collaborators showed that the peptide blocks this channel subtype with an $\mathrm{IC}_{50}$ value slightly below $100 \mathrm{nM}$ (Gonçalves et al., 2018b), which is not markedly different from the value we obtained in standardized conditions. These results allow a better understanding of the mechanisms of in vivo motor toxicity sideeffects of HwTx-IV (Liu et al., 2014b; Deuis et al., 2016). More recently, a large-scale SAR investigation was performed with the help of recombinant HwTx-IV analogues tested on both $\mathrm{hNa}_{\mathrm{V}} 1.7$ and $\mathrm{hNa}_{\mathrm{V}} 1.2$ and, occasionally, on a larger panel of other $\mathrm{hNa}$ subtypes, without extensively reporting on the activity of wildtype HwTx-IV on $\mathrm{hNa}_{\mathrm{V}} 1.6$ (Neff et al., 2020).

\section{Lessons From SAR Studies to Determine HwTx-IV Critical Residues for hNav1.7 Block}

Several objectives have been pursued in HwTx-IV SAR studies, namely: 1) defining the site of binding of the peptide onto the channel, 2) determining the peptide pharmacophore to get a clear picture of the peptide docking on the channel, 3) clarifying the relationships between the peptide and the channel lipid environment, and 4) improving both the peptide potency and selectivity. The two first aims are closely interconnected.

As stated above (see Introduction section), the blocking effect of HxTx-IV on $\mathrm{hNa}_{\mathrm{V}} 1.7$ is due to its binding onto the voltagesensor of domain II of the channel subtype. As a result, HwTxIV traps this voltage-sensor in the inward closed configuration (Xiao et al., 2008), which logically inhibits the gating currents conveyed by domain II movement (Xiao et al., 2014). More precisely, the binding occurs onto the S3-S4 linker of domain II. Amino acid residues $\mathrm{D}^{816}$ and $\mathrm{E}^{818}$ of $\mathrm{hNa}_{\mathrm{V}} 1.7$ are involved in this binding since mutating these residues reduces the peptide potency by over 60-fold (Xiao et al., 2008; Xiao et al., 2010). Conversely, mutations in $\mathrm{hNa}_{\mathrm{V}} 1.4\left(\mathrm{~N}^{655} \mathrm{D}, \mathrm{Q}^{657} \mathrm{E}\right)$ or $\mathrm{hNa}_{\mathrm{V}} 1.5$ $\left(\mathrm{R}^{812} \mathrm{D}, \mathrm{S}^{814} \mathrm{E}\right)$, aimed at instating $\mathrm{hNa} \mathrm{V}_{\mathrm{V}} 1.7$ residues, were shown to produce a gain of HwTx-IV potency on these channel subtypes. A larger scale investigation refined the pictures of $\mathrm{hNa}_{\mathrm{V}} 1.7$ channel residues involved in binding HwTx-IV, and identified a total of five amino acids, one belonging to the S1-S2 linker $\left(\mathrm{E}^{753}\right)$ and the four remaining ones being part of the S3-S4 linker $\left(\mathrm{E}^{811}, \mathrm{~L}^{814}, \mathrm{D}^{816}\right.$ and $\mathrm{E}^{818}$ ) (Xiao et al., 2011). This cluster of 5 residues defines an EELDE motif (herein defined as $\mathrm{E}_{1} \mathrm{E}_{2} \mathrm{~L}_{3} \mathrm{D}_{4} \mathrm{E}_{5}$ for convenience), and thus suggests that the interaction largely relies on electrostatic interactions. It is worth noting that HwTx-IV acts in an odd manner on the voltage-sensor of domain II since no clear voltage-dependent effect of the toxin has been reported in the literature, except maybe for very strong depolarizing pulses meant to favor toxin dissociation (Gonçalves et al., 2018b). However, SAR studies may potentially reveal new HwTx-IV analogues displaying voltage-dependent effect and, therefore, it would be of interest to check the voltage-dependence or lack thereof of the best toxin analogues.

To get a hint of how the toxin interacts with its binding site on $\mathrm{hNa}_{\mathrm{V}} 1.7$, several initiatives were launched, including 1) complete SAR investigation of the contribution of HwTx-IV residues, 2) cryo-EM analyses and 3) the use of photocrosslinking probes derived from HwTx-IV.

Concerning the SAR studies on HwTx-IV, the emerging picture is that the couple of residues, $\mathrm{W}^{30}$ and $\mathrm{K}^{32}$, are required to preserve peptide activity onto $\mathrm{hNa}_{\mathrm{V}} 1.7$ (Minassian et al., 2013; Revell et al., 2013; Neff et al., 2020). Modest reduction in potencies (<10-fold) are observed for $\mathrm{F}^{6} \mathrm{~A}, \mathrm{~K}^{18} \mathrm{~A}, R^{26} \mathrm{~A}, \mathrm{~K}^{27} \mathrm{~A}$ and $\mathrm{Y}^{33} \mathrm{~A}$, all other substitutions being neutral $\left(\mathrm{L}^{3} \mathrm{~A}, \mathrm{~S}^{9} \mathrm{~A}, \mathrm{P}^{11} \mathrm{~A}\right.$, $\left.S^{12} A, D^{14} A, L^{22} A, S^{25} A\right)$ or modestly beneficial ( $E^{1} A, E^{4} A, K^{7} A$, $\mathrm{N}^{10} \mathrm{~A}, \mathrm{Q}^{12} \mathrm{~A}, \mathrm{~S}^{19} \mathrm{~A}, \mathrm{~S}^{20} \mathrm{~A}, \mathrm{~K}^{21} \mathrm{~A}, \mathrm{~V}^{23} \mathrm{~A}, \mathrm{~T}^{28} \mathrm{~A}, R^{29} \mathrm{~A}, \mathrm{Q}^{34} \mathrm{~A}$ and $\left.\mathrm{I}^{35} \mathrm{~A}\right)$ (Revell et al., 2013). These conclusions are relatively well supported by the data of Minassian and collaborators, although these authors use mainly recombinant HwTx-IV, lacking C-terminal amidation and possessing some extra residues in the sequence (Minassian et al., 2013).

For the cryo-EM investigation, the authors replaced the S3-S4 linker of the $\mathrm{NaChBac}$ sequence by the one of $\mathrm{hNa}_{\mathrm{V}} 1.7$, and illustrated the interaction of HwTx-IV with this chimera channel (Gao et al., 2020). They concluded that $K^{27}$ is located close to $E_{2}$, that $\mathrm{K}^{32}$ interacts with $\mathrm{E}_{2}$, and that $\mathrm{Y}^{33}$ forms hydrogen bonds with the backbone groups of $\mathrm{L}_{3}$ and an adjacent $\mathrm{A}$ residue. Globally, positive residues of HwTx-IV $R^{26}, \mathrm{~K}^{27}$ and $\mathrm{K}^{32}$ are in close vicinity of the channel, whereas the hydrophobic residues $\mathrm{I}^{5}$, $\mathrm{F}^{6}$ and $\mathrm{W}^{30}$ are immersed in the lipid bilayer. However, chimera approaches may not perfectly reconstitute the wild-type HwTxIV binding site. For instance, the $\mathrm{K}^{32} \mathrm{~A}$ mutation in HwTx-IV barely impacts peptide effect on the chimera channel (Gao et al., 2020) while, in our study, a similar $K^{32} \mathrm{~N}$ mutation prevents the HwTx-IV-induced block of $\mathrm{hNa}_{\mathrm{V}} 1.7$ (see Figures 2A,C).

The model of interaction was refined by an elegant study that used photocrosslinking probes derived from HwTx-IV and the full-length $\mathrm{hNa}_{\mathrm{V}} 1.7$ (Tzakoniati et al., 2020). L-photomethionine was introduced in HwTx-IV sequence to replace one of 6 residues $\left(\mathrm{I}^{5}, \mathrm{~K}^{7}, \mathrm{~K}^{21}, \mathrm{~K}^{27}, R^{29}, \mathrm{I}^{35}\right)$ deemed proximal to other crucial residues involved in toxin interaction. Among these 6 new analogues, only 2 photoprobes, with substitutions at position 27 or 29 , crosslinked to $\mathrm{hNa}_{\mathrm{V}} 1.7$ with high efficiency: photoprobe 27 to the peptide ${ }^{808}$ SLVE $^{811}$ that belongs to the S3 helix, and photoprobe 29 to the motif ${ }^{758} \mathrm{TEEF}^{761}$ of the S1-S2 loop. These data support the concept that $\mathrm{K}^{27}$ of HwTx-IV interacts with $\mathrm{E}_{2}$ of the $\mathrm{E}_{1} \mathrm{E}_{2} \mathrm{~L}_{3} \mathrm{D}_{4} \mathrm{E}_{5}$ motif and $R^{29}$ with a negatively charged residue of S1-S2 loop (most likely $\mathrm{E}^{759}$ ) that differs from $\mathrm{E}_{1}$. In this way, they contradict the docking model of Minassian and collaborators that suggested an interaction between $\mathrm{K}^{27}$ and $\mathrm{E}_{5}$ rather than $\mathrm{E}_{2}$ 
(Minassian et al., 2013). The refined docking model supports the idea that $\mathrm{F}^{6}, \mathrm{~W}^{30}$ and $\mathrm{Y}^{33}$ interact with the lipid bilayer. The crucial $\mathrm{K}^{32}$ residue would also interact with $\mathrm{E}_{2}$ of the binding motif (Figure 7). According to a summary of this docking, HwTx-IV I ${ }^{35}$ would also interact with $\mathrm{L}_{3}$. The fact that the $R^{29} \mathrm{~A}$ mutation hardly affects $\mathrm{HwTx}-\mathrm{IV}$ potency for $\mathrm{hNa}_{\mathrm{V}} 1.7$ (Revell et al., 2013) would indicate that HwTx-IV interaction with the S1-S2 loop has little functional implication for the mechanism of channel block.

How do these data fit with what we know about the toxin/lipid interactions? Part of the conclusions drawn about the definition of HwTx-IV pharmacophore was complexified by the fact that the peptide, besides binding to the targeted channel, also requires partitioning into the lipid membrane for the access to the binding site. This has led to the concept of a three-way interaction for the mechanism of action of the toxin (Agwa et al., 2017), which complicates the design of new analogues as exemplified by the case of protoxin II (Montnach et al., 2021). From the various docking models or Cryo-EM structure previously published (Minassian et al., 2013; Gao et al., 2020; Neff et al., 2020; Tzakoniati et al., 2020), several residues of HwTx-IV are susceptible to directly interact with lipids $\left(\mathrm{I}^{5}, \mathrm{~F}^{6}, R^{29}, \mathrm{~W}^{30}\right.$, $\left.\mathrm{Y}^{33}\right)$. By mutating non-essential residues for the interaction with $\mathrm{hNa}_{\mathrm{V}} 1.7$, it was shown that the combined mutagenesis of $E^{1} G, E^{4} G, F^{6} W$ and $Y^{33} W$ produces an HwTx-IV analogue with increased ability to bind membrane lipids, a property that in turns explains the increased potency of this analogue for $\mathrm{hNa}_{\mathrm{V}} 1.7$ (Agwa et al., 2017). In this mutated analogue, two of the residues are suspected to interact directly with lipids $\left(\mathrm{W}^{30}\right.$ and $\mathrm{Y}^{33}$ ), whereas the two other residues may hamper toxin partitioning into the lipid bilayer because of the negative charges associated to E residues. In wild-type HwTx-IV, the $\mathrm{E}^{4}$ residue forms a salt bridge with $\mathrm{K}^{7}$, possibly stabilizing the peptide fold. Mutation of $\mathrm{E}^{4}$ to $\mathrm{G}^{4}$ appears to increase the potency for $\mathrm{hNa}_{\mathrm{V}} 1.7$ by improving permeability into the membrane (Klint et al., 2015) and the interaction surface of the peptide with the channel (Figure 7). If in addition the authors mutate a non-essential positively charged residue, $R^{26} \mathrm{~A}$, a further improvement in lipid affinity is observed, also accompanied by an additional improvement in toxin potency for $\mathrm{hNa}_{\mathrm{V}} 1.7$ (Agwa et al., 2020). The lesson from this work is that it is possible to enhance lipid partitioning of a toxin either directly by acting on residues that interact with lipids or indirectly by altering the global hydrophobicity profile of the peptide.

It is therefore clear from SAR and docking studies that there are three ways to alter potency and selectivity of HwTx-IV, namely by 1) mutating residues involved in binding onto the channel itself, 2) substituting residues involved in peptide/lipid interactions, and 3) indirectly playing on the surface charge or hydrophobicity profile of the peptide. By intervening on one or several of these factors, it is possible to modify peptide selectivity. Earlier efforts in that direction were performed by altering the relative potency of $\mathrm{HwTx}-\mathrm{IV}$ for $\mathrm{hNa}_{\mathrm{V}} 1.7$ and $\mathrm{hNa}_{\mathrm{V}}$ 1.2. For instance, the $R^{29} \mathrm{~A}$ mutation was shown to increase potency for $h \mathrm{ha}_{\mathrm{V}} 1.7$ but to considerably reduce the one for $\mathrm{hNa}_{\mathrm{V}} 1.2$ (Minassian et al., 2013). This was possibly due to a weakened electrostatic interaction with the EELNE motif of $\mathrm{hNa}_{\mathrm{V}} 1.2$. It was also found that the triple mutant $E^{1} G / E^{4} G / Y^{33} W$ (but as recombinant protein, i.e. without $\mathrm{C}$-terminal amidation) has an improved $\mathrm{IC}_{50}$ value for $\mathrm{hNa}_{\mathrm{V}} 1.7$, but without increased activity for either $\mathrm{hNa}_{\mathrm{V}} 1.1, \mathrm{hNa}_{\mathrm{V}} 1.2, \mathrm{hNa}_{\mathrm{V}} 1.3, \mathrm{hNa}_{\mathrm{V}} 1.5$ or hNa 1.6 (Rahnama et al., 2017). The analogue with 5 mutations $\left(\mathrm{E}^{1} \mathrm{G} / \mathrm{E}^{4} \mathrm{G} / \mathrm{F}^{6} \mathrm{~W} / R^{26} \mathrm{~A} / \mathrm{Y}^{3} \mathrm{~W}\right)$, not only possessed a better potency for $\mathrm{hNa}_{\mathrm{V}} 1.7$, but also an improved selectivity profile over $\mathrm{hNa}_{\mathrm{V}} 1.2$ (27 times more selective) (Agwa et al., 2020). The same analogue produced a $\mathrm{hNa}_{\mathrm{V}} 1.7 / \mathrm{hNa}_{\mathrm{V}} 1.6$ selectivity ratio of 11 .

\section{The Pros and Cons of SAR Studies Using HwTx-IV as Template for Selectivity Alterations}

The first issue to be discussed is without any doubts linked to the strategy employed to perform the SAR investigation. With an economical perspective, it appears logic to search for analogues that are produced by recombinant means as production costs are lower and yields higher. This method was chosen by several private actors (MedImmune, Janssen Research and Development) but not all (Genentech). Clearly, a comparison of our data testing HwTx-IV analogues onto $\mathrm{hNa}_{\mathrm{V}} 1.7$ illustrates that the presence or not of the C-terminal amidation has important consequences on the interpretation of the SAR data. Interesting differences were noted. For instance, a substitution of $\mathrm{T}^{28}$ was considered as beneficial for HwTx-IV potency towards $\mathrm{hNa}_{\mathrm{V}} 1.7$ in its recombinant form (Revell et al., 2013), while in our hands it was clearly detrimental. Also, while for both $\mathrm{hNa}_{\mathrm{V}} 1.7$ and $\mathrm{hNa}_{\mathrm{V}} 1.6$ channel subtypes, a HwTx-IV analogue with a carboxylated C-terminus is synonym of loss of potency, there are interesting compensatory mutations capable to restore peptide potency. Part of the beneficial effect of C-terminal amidation could be reproduced by the introduction of an extra $\mathrm{K}^{36}$ residue, even if the $\mathrm{C}$-terminus was still carboxylated (HwTxIV $\mathrm{K}^{36} / \mathrm{C}_{\text {ter }} \mathrm{COOH}$ ), suggesting that the amine function of the lateral chain could substitute favorably to the C-terminal amidation. Gain of potency for $\mathrm{hNa}_{\mathrm{V}} 1.7$ has been observed earlier if an extra Gly residue was incorporated at position 36 along with a C-terminal amidation (Sermadiras et al., 2013). The gain of potency we observed with $\mathrm{HwTx}-\mathrm{IV} \mathrm{K}^{36} / \mathrm{C}_{\text {ter }} \mathrm{COOH}$ was true for the $\mathrm{hNa}_{\mathrm{V}} 1.7$ target but not for the $\mathrm{hNa}_{\mathrm{V}} 1.6$ channel subtype, suggesting that the C-terminal amidation is a function of interest to create differences in selectivity between the two channel subtypes. These observations also question the "true" selectivity profiles published with recombinant HwTx-IV. Interestingly, mutation of $\mathrm{E}^{4}$ also largely compensated for the loss of potency induced by the carboxylated C-terminus sequence. This time, the compensation at work was valid for both channel subtypes, suggesting that all efforts to build recombinant analogues with increased potencies for $\mathrm{Na}_{V}$ channel subtypes should incorporate an $\mathrm{E}^{4}$ mutation.

The question that arises now is how far one can expect to go with efforts dedicated at improving selectivity for a given $\mathrm{Na}_{\mathrm{V}}$ subtype? In the work we launched, the task was challenging since the beginning of the project because the crucial $\mathrm{E}_{1} \mathrm{E}_{2} \mathrm{~L}_{3} \mathrm{D}_{4} \mathrm{E}$ motif is conserved in $\mathrm{hNa}_{\mathrm{V}}$ 1.6. As a reminder, this motif becomes 
$\mathrm{E}_{1} \mathrm{E}_{2} \mathrm{~L}_{3} \mathrm{~N}_{4} \mathrm{E}_{5}$ in $\mathrm{hNa} \mathrm{V}_{\mathrm{V}} 1.2$, a channel subtype that was used as template for earlier SAR studies aimed at altering peptide selectivity. We are aware that these earlier efforts did not necessarily constitute the best guidelines for producing analogues differentially affecting $\mathrm{hNa}_{\mathrm{V}} 1.7$ and $\mathrm{hNa}_{\mathrm{V}} 1.6$ for two reasons: 1 ) the $\mathrm{hNa}_{\mathrm{V}} 1.6$ binding motif differs from the $\mathrm{hNa}_{\mathrm{V}} 1.2$ motif, and 2) the SAR studies were all performed with recombinant peptides that in addition possess several extra residues at their C-terminus (Neff et al., 2020). Nevertheless, positions that differentially affected the relative $\mathrm{hNa}_{\mathrm{V}} 1.7 / \mathrm{hNa}_{\mathrm{V}} 1.2$ selectivity ratio when mutated were $\mathrm{F}^{6}, \mathrm{~K}^{18}, R^{26}, \mathrm{~K}^{27}$ and $\mathrm{I}^{35}$ (Minassian et al., 2013). In contrast to two reports (Minassian et al., 2013; Neff et al., 2020), we found that the $\mathrm{K}^{26}$ mutation preferentially lowers potency for $\mathrm{hNa}_{\mathrm{V}} 1.7$. More coherent was the fact that the $\mathrm{K}^{18} \mathrm{~A}$ mutation improves potency for $\mathrm{hNa}_{\mathrm{V}} 1.7$ while slightly reducing it for $\mathrm{hNa}_{\mathrm{V}} 1.6$, although less drastically than for $\mathrm{hNa}_{\mathrm{V}} 1.2$ (Minassian et al., 2013). In our hands, the most interesting positions tested to differentially affect the selectivity between $\mathrm{hNa}_{\mathrm{V}} 1.7$ and $\mathrm{hNa}_{\mathrm{V}} 1.6$ were $\mathrm{E}^{1}, \mathrm{E}^{4}, R^{26}$ or the combinations $\mathrm{E}^{1} / \mathrm{E}^{4}, \mathrm{E}^{4} / R^{26}$ and $\mathrm{E}^{1} / \mathrm{E}^{4} / \mathrm{K}^{18}$. For obvious economic reasons, this was not an as exhaustive work as wished to test all possible positions of HwTx-IV sequence and perform a full comparison with the work of Neff and collaborators (Neff et al., 2020). Nevertheless, several conclusions could be reached. First, it is possible to further increase the potency of HwTx-IV for $\mathrm{hNa}_{\mathrm{V}} 1.7$ in spite of an excellent starting affinity. However, the optimization remains in the range of 10-fold maximum, suggesting that there are limitations reached maybe because of the complexity in the docking to the channel combined to the need for partitioning into the lipid membrane. Second, it is clearly possible to optimize potency for $\mathrm{hNa}_{\mathrm{V}} 1.6$ in spite of similarities in the target-binding site, and the extent of this optimization is greater for this subtype than for $\mathrm{hNa}_{\mathrm{V}}$ 1.7. Thirdly, there must be differences somewhere in the docking onto $\mathrm{hNa}_{\mathrm{V}} 1.6$ compared to $\mathrm{hNa}_{\mathrm{V}} 1.7$ because some analogues clearly affected the selectivity ratios. One in particular looks as a promising $\mathrm{hNa} \mathrm{V}_{\mathrm{V}} 1.7$ target (HwTx-IV $\mathrm{E}^{4} \mathrm{~K} / \mathrm{R}^{26} \mathrm{~A} / \mathrm{Y}^{33} \mathrm{~W}$ ) as it both improves the potency on this channel type and decreases the one on $\mathrm{hNa}_{\mathrm{V}} 1.6$, which should lead to decreased side effects.

\section{REFERENCES}

Agwa, A. J., Lawrence, N., Deplazes, E., Cheneval, O., Chen, R. M., Craik, D. J., et al. (2017). Spider Peptide Toxin HwTx-IV Engineered to Bind to Lipid Membranes Has an Increased Inhibitory Potency at Human Voltage-Gated Sodium Channel hNa V 1.7. Biochim. Biophys. Acta (Bba) - Biomembranes 1859, 835-844. doi:10.1016/j.bbamem.2017.01.020

Agwa, A. J., Tran, P., Mueller, A., Tran, H. N. T., Deuis, J. R., Israel, M. R., et al. (2020). Manipulation of a Spider Peptide Toxin Alters its Affinity for Lipid Bilayers and Potency and Selectivity for Voltage-Gated Sodium Channel Subtype 1.7. J. Biol. Chem. 295, 5067-5080. doi:10.1074/ jbc.ra119.012281

Bordon, K. d. C. F., Cologna, C. T., Fornari-Baldo, E. C., Pinheiro-Júnior, E. L., Cerni, F. A., Amorim, F. G., et al. (2020). From Animal Poisons and Venoms to Medicines: Achievements, Challenges and Perspectives in Drug Discovery. Front. Pharmacol. 11, 1132. doi:10.3389/fphar.2020.01132

\section{CONCLUSION}

Overall, this work demonstrates that it is possible to create a number of new HwTx-IV analogues with increased potencies for both channel subtypes up to the point of equal potencies on $\mathrm{hNa}_{\mathrm{V}} 1.7$ and $\mathrm{hNa}_{\mathrm{V}} 1.6$. However, it was never possible to create an inversion of the selectivity ratio with a loss of potency towards $\mathrm{hNa}_{\mathrm{V}} 1.7$ combined with nanomolar affinity for $\mathrm{hNa}_{\mathrm{V}}$ 1.6. For such a result, we suggest that it is better to start SAR investigation on a toxin that initially has better affinity towards $\mathrm{Na}_{\mathrm{V}} 1.6$.

\section{DATA AVAILABILITY STATEMENT}

The raw data supporting the conclusions of this article will be made available by the authors, without undue reservation.

\section{AUTHOR CONTRIBUTIONS}

LL, JM, BP, BO-M, KK, SL and SN performed and analysed the experiments; EB and MDW wrote the manuscript; CC, SW, MW and $\mathrm{RB}$ designed and supervised the production of HwTx-IV analogues; DS reviewed and edited the paper. RB and MW acquired the funding. All authors read and approved the final manuscript.

\section{FUNDING}

This work was supported by the Agence Nationale de la Recherche (grant number ANR-11-LABX-0015 to MDW), the Fondation Leducq in the frame of its program of "Equipement de recherche et plateformes technologiques", the Région Pays de la Loire (nouvelle équipe, grant number 2016-11092/11,093 to MDW), and the European FEDER (grant number 2017/FEDER/PL0014592 to MDW). LL is supported by a CIFRE fellowship jointly financed by the ANRT and Smartox Biotechnology, while JM is supported by the Agence Nationale de la Recherche (grant number ANR-18CE19-0024-02 to MDW).

Cardoso, F. C., and Lewis, R. J. (2018). Sodium Channels and Pain: from Toxins to Therapies. Br. J. Pharmacol. 175, 2138-2157. doi:10.1111/bph.13962

Cardoso, F. C., and Lewis, R. J. (2019). Structure-Function and Therapeutic Potential of Spider Venom-Derived Cysteine Knot Peptides Targeting Sodium Channels. Front. Pharmacol. 10, 366. doi:10.3389/fphar.2019.00366

Cox, J. J., Reimann, F., Nicholas, A. K., Thornton, G., Roberts, E., Springell, K., et al. (2006). An SCN9A Channelopathy Causes Congenital Inability to Experience Pain. Nature 444, 894-898. doi:10.1038/nature05413

Cuesta, S. A., and Meneses, L. (2021). The Role of Organic Small Molecules in Pain Management. Molecules 26. doi:10.3390/molecules26134029

Deuis, J. R., Wingerd, J. S., Winter, Z., Durek, T., Dekan, Z., Sousa, S. R., et al. (2016). Analgesic Effects of GpTx-1, PF-04856264 and CNV1014802 in a Mouse Model of NaV1.7-Mediated Pain. Toxins (Basel) 8. doi:10.3390/ toxins 8030078

Dongol, Y., Cardoso, F. C., and Lewis, R. J. (2019). Spider Knottin Pharmacology at Voltage-Gated Sodium Channels and Their Potential to Modulate Pain Pathways. Toxins (Basel) 11. doi:10.3390/toxins11110626 
Estacion, M., Dib-Hajj, S. D., Benke, P. J., Te Morsche, R. H. M., Eastman, E. M., Macala, L. J., et al. (2008). NaV1.7 Gain-Of-Function Mutations as a Continuum: A1632E Displays Physiological Changes Associated with Erythromelalgia and Paroxysmal Extreme Pain Disorder Mutations and Produces Symptoms of Both Disorders. J. Neurosci. 28, 11079-11088. doi:10.1523/jneurosci.3443-08.2008

Flinspach, M., Xu, Q., Piekarz, A. D., Fellows, R., Hagan, R., Gibbs, A., et al. (2017). Insensitivity to Pain Induced by a Potent Selective Closed-State Nav1.7 Inhibitor. Sci. Rep. 7, 39662. doi:10.1038/srep39662

Focken, T., Liu, S., Chahal, N., Dauphinais, M., Grimwood, M. E., Chowdhury, S., et al. (2016). Discovery of Aryl Sulfonamides as Isoform-Selective Inhibitors of NaV1.7 with Efficacy in Rodent Pain Models. ACS Med. Chem. Lett. 7, 277-282. doi:10.1021/acsmedchemlett.5b00447

Gao, S., Valinsky, W. C., On, N. C., Houlihan, P. R., Qu, Q., Liu, L., et al. (2020). Employing $\mathrm{NaChBac}$ for Cryo-EM Analysis of Toxin Action on Voltage-Gated Na+channels in Nanodisc. Proc. Natl. Acad. Sci. USA 117, 14187-14193. doi:10.1073/pnas.1922903117

Gonçalves, T. C., Benoit, E., Partiseti, M., and Servent, D. (2018a). The NaV1.7 Channel Subtype as an Antinociceptive Target for Spider Toxins in Adult Dorsal Root Ganglia Neurons. Front. Pharmacol. 9, 1000. doi:10.3389/ fphar.2018.01000

Gonçalves, T. C., Boukaiba, R., Molgó, J., Amar, M., Partiseti, M., Servent, D., et al. (2018b). Direct Evidence for High Affinity Blockade of NaV1.6 Channel Subtype by Huwentoxin-IV Spider Peptide, Using Multiscale Functional Approaches. Neuropharmacology 133, 404-414. doi:10.1016/ j.neuropharm.2018.02.016

Klint, J. K., Chin, Y. K.-Y., and Mobli, M. (2015). Rational Engineering Defines a Molecular Switch that Is Essential for Activity of Spider-Venom Peptides against the Analgesics Target NaV1.7. Mol. Pharmacol. 88, 1002-1010. doi:10.1124/mol.115.100784

Klint, J. K., Senff, S., Rupasinghe, D. B., Er, S. Y., Herzig, V., Nicholson, G. M., et al. (2012). Spider-venom Peptides that Target Voltage-Gated Sodium Channels: Pharmacological Tools and Potential Therapeutic Leads. Toxicon 60, 478-491. doi:10.1016/j.toxicon.2012.04.337

Liu, Y., Wu, Z., Tang, D., Xun, X., Liu, L., Li, X., et al. (2014b). Analgesic Effects of Huwentoxin-IV on Animal Models of Inflammatory and Neuropathic Pain. Protein Pept. Lett. 21, 153-158. doi:10.2174/09298665113206660119

Liu, Y., Tang, J., Zhang, Y., Xun, X., Tang, D., Peng, D., et al. (2014a). Synthesis and Analgesic Effects of $\mu$-TRTX-Hhn1b on Models of Inflammatory and Neuropathic Pain. Toxins 6, 2363-2378. doi:10.3390/toxins6082363

Macsari, I., Besidski, Y., Csjernyik, G., Nilsson, L. I., Sandberg, L., Yngve, U., et al. (2012). 3-Oxoisoindoline-1-carboxamides: Potent, State-dependent Blockers of Voltage-Gated Sodium Channel NaV1.7 with Efficacy in Rat Pain Models. J. Med. Chem. 55, 6866-6880. doi:10.1021/jm300623u

Minassian, N. A., Gibbs, A., Shih, A. Y., Liu, Y., Neff, R. A., Sutton, S. W., et al. (2013). Analysis of the Structural and Molecular Basis of Voltage-Sensitive Sodium Channel Inhibition by the Spider Toxin Huwentoxin-IV ( $\mu$-TRTXHh2a). J. Biol. Chem. 288, 22707-22720. doi:10.1074/jbc.m113.461392

Montnach, J., De Waard, S., Nicolas, S., Burel, S., Osorio, N., Zoukimian, C., et al. (2021). Fluorescent- and Tagged-protoxin II Peptides: Potent Markers of the Na V 1.7 Channel Pain Target. Br. J. Pharmacol. 178, 2632-2650. doi:10.1111/bph.15453

Neff, R. A., Flinspach, M., Gibbs, A., Shih, A. Y., Minassian, N. A., Liu, Y., et al. (2020). Comprehensive Engineering of the Tarantula Venom Peptide Huwentoxin-IV to Inhibit the Human Voltage-Gated Sodium Channel hNav1.7. J. Biol. Chem. 295, 1315-1327. doi:10.1074/jbc.ra119.011318

Nguyen, H. N., Bregman, H., Buchanan, J. L., Du, B., Feric, E., Huang, L., et al. (2012). Discovery and Optimization of Aminopyrimidinones as Potent and State-dependent Nav1.7 Antagonists. Bioorg. Med. Chem. Lett. 22, 1055-1060. doi:10.1016/j.bmcl.2011.11.111

Peng, K., Shu, Q., Liu, Z., and Liang, S. (2002). Function and Solution Structure of Huwentoxin-IV, a Potent Neuronal Tetrodotoxin (TTX)-sensitive Sodium Channel Antagonist from Chinese Bird Spider Selenocosmia Huwena. J. Biol. Chem. 277, 47564-47571. doi:10.1074/jbc.m204063200

Rahnama, S., Deuis, J. R., Cardoso, F. C., Ramanujam, V., Lewis, R. J., Rash, L. D., et al. (2017). The Structure, Dynamics and Selectivity Profile of a NaV1.7 Potency-Optimised Huwentoxin-IV Variant. PLoS One 12, e0173551. doi:10.1371/journal.pone.0173551
Revell, J. D., Lund, P.-E., Linley, J. E., Metcalfe, J., Burmeister, N., Sridharan, S., et al. (2013). Potency Optimization of Huwentoxin-IV on hNav1.7: a Neurotoxin TTX-S Sodium-Channel Antagonist from the Venom of the Chinese Bird-Eating Spider Selenocosmia Huwena. Peptides 44, 40-46. doi:10.1016/j.peptides.2013.03.011

Sermadiras, I., Revell, J., Linley, J. E., Sandercock, A., and Ravn, P. (2013). Recombinant Expression and In Vitro Characterisation of Active Huwentoxin-IV. PLoS One 8, e83202. doi:10.1371/journal.pone.0083202

Shen, H., Liu, D., Wu, K., Lei, J., and Yan, N. (2019). Structures of Human Na V 1.7 Channel in Complex with Auxiliary Subunits and Animal Toxins. Science 363, 1303-1308. doi:10.1126/science.aaw2493

Sun, S., Jia, Q., Zenova, A. Y., Chafeev, M., Zhang, Z., Lin, S., et al. (2014). The Discovery of Benzenesulfonamide-Based Potent and Selective Inhibitors of Voltage-Gated Sodium Channel Na V 1.7. Bioorg. Med. Chem. Lett. 24, 4397-4401. doi:10.1016/j.bmcl.2014.08.017

Trim, C. M., Byrne, L. J., and Trim, S. A. (2021). Utilisation of Compounds from Venoms in Drug Discovery. Prog. Med. Chem. 60, 1-66. doi:10.1016/ bs.pmch.2021.01.001

Tzakoniati, F., Xu, H., Li, T., Garcia, N., Kugel, C., Payandeh, J., et al. (2020). Development of Photocrosslinking Probes Based on Huwentoxin-IV to Map the Site of Interaction on Nav1.7. Cel Chem. Biol. 27, 306-313. doi:10.1016/ j.chembiol.2019.10.011

Wu, Y.-J., Guernon, J., Mcclure, A., Luo, G., Rajamani, R., Ng, A., et al. (2017). Discovery of Non-zwitterionic Aryl Sulfonamides as Nav1.7 Inhibitors with Efficacy in Preclinical Behavioral Models and Translational Measures of Nociceptive Neuron Activation. Bioorg. Med. Chem. 25, 5490-5505. doi:10.1016/j.bmc.2017.08.012

Xiao, Y., Bingham, J.-P., Zhu, W., Moczydlowski, E., Liang, S., and Cummins, T. R. (2008). Tarantula Huwentoxin-IV Inhibits Neuronal Sodium Channels by Binding to Receptor Site 4 and Trapping the Domain Ii Voltage Sensor in the Closed Configuration. J. Biol. Chem. 283, 27300-27313. doi:10.1074/ jbc.m708447200

Xiao, Y., Blumenthal, K., and Cummins, T. R. (2014). Gating-pore Currents Demonstrate Selective and Specific Modulation of Individual Sodium Channel Voltage-Sensors by Biological Toxins. Mol. Pharmacol. 86, 159-167. doi:10.1124/mol.114.092338

Xiao, Y., Blumenthal, K., Jackson, J. O., 2nd, Liang, S., and Cummins, T. R. (2010). The Tarantula Toxins ProTx-II and Huwentoxin-IV Differentially Interact with Human Nav1.7 Voltage Sensors to Inhibit Channel Activation and Inactivation. Mol. Pharmacol. 78, 1124-1134. doi:10.1124/mol.110.066332

Xiao, Y., Jackson, J. O., 2nd, Liang, S., and Cummins, T. R. (2011). Common Molecular Determinants of Tarantula Huwentoxin-IV Inhibition of $\mathrm{Na}+$ Channel Voltage Sensors in Domains II and IV. J. Biol. Chem. 286, 27301-27310. doi:10.1074/jbc.m111.246876

Conflict of Interest: Authors KK, SL, SW, and CC were employed by company Xenon Pharmaceuticals. Authors BT, CC, RB, and LL were employed by company Smartox Biotechnology. MDW is a consultant and founder of Smartox Biotechnology.

The remaining authors declare that the research was conducted in the absence of any commercial or financial relationships that could be construed as a potential conflict of interest.

Publisher's Note: All claims expressed in this article are solely those of the authors and do not necessarily represent those of their affiliated organizations, or those of the publisher, the editors, and the reviewers. Any product that may be evaluated in this article, or claim that may be made by its manufacturer, is not guaranteed or endorsed by the publisher.

Copyright (c) 2021 Lopez, Montnach, Oliveira-Mendes, Khakh, Thomas, Lin, Caumes, Wesolowski, Nicolas, Servent, Cohen, Béroud, Benoit and De Waard. This is an open-access article distributed under the terms of the Creative Commons Attribution License (CC BY). The use, distribution or reproduction in other forums is permitted, provided the original author(s) and the copyright owner(s) are credited and that the original publication in this journal is cited, in accordance with accepted academic practice. No use, distribution or reproduction is permitted which does not comply with these terms. 